\title{
Inhibition of cyclin D1 phosphorylation on threonine-286 prevents its rapid degradation via the ubiquitin- proteasome pathway
}

\author{
J. Alan Diehl, ${ }^{1,2}$ Frederique Zindy, ${ }^{2}$ and Charles J. Sherr ${ }^{1-3}$ \\ ${ }^{1}$ Howard Hughes Medical Institute, ${ }^{2}$ Department of Tumor Cell Biology, St. Jude Children's Research Hospital, \\ Memphis, Tennessee 38105 USA
}

The expression of D-type G1 cyclins and their assembly with their catalytic partners, the cyclin-dependent kinases 4 and 6 (CDK4 and CDK6), into active holoenzyme complexes are regulated by growth factor-induced signals. In turn, the ability of cyclin D-dependent kinases to trigger phosphorylation of the retinoblastoma $(R b)$ protein in the mid- to late $G_{1}$ phase of the cell cycle makes the inactivation of $R b^{\prime} s$ growth suppressive function a mitogen-dependent step. The ability of D-type cyclins to act as growth factor sensors depends not only on their rapid induction by mitogens but also on their inherent instability, which ensures their precipitous degradation in cells deprived of growth factors. However, the mechanisms governing the turnover of D-type cyclins have not yet been elucidated. We now show that cyclin D1 turnover is governed by ubiquitination and proteasomal degradation, which are positively regulated by cyclin D1 phosphorylation on threonine-286. Although "free" or CDK4-bound cyclin D1 molecules are intrinsically unstable $\left(t^{1 / 2}<30 \mathrm{~min}\right)$, a cyclin D1 mutant (T286A) containing an alanine for threonine-286 substitution fails to undergo efficient polyubiquitination in an in vitro system or in vivo, and it is markedly stabilized $\left(t^{1 / 2} \sim 3.5 \mathrm{hr}\right)$ when inducibly expressed in either quiescent or proliferating mouse fibroblasts. Phosphorylation of cyclin D1 on threonine-286 also occurs in insect Sf9 cells, and although the process is enhanced significantly by the binding of cyclin D1 to CDK4, it does not depend on CDK4 catalytic activity. This implies that another kinase can phosphorylate cyclin D1 to accelerate its destruction and points to yet another means by which cyclin D-dependent kinase activity may be exogenously regulated.

[Key Words: Cyclin D1 phosphorylation; Rb protein; cyclin D destruction; ubiquitin-proteasome pathway]

Received January 23, 1997; revised version accepted March 6, 1997.

Cell cycle transitions are governed by distinct families of cyclin-dependent kinases (CDKs) whose activities are determined by cyclin binding, by both positive and negative regulatory phosphorylations, and by polypeptide CDK inhibitors (Norbury and Nurse 1992; Reed 1992; Morgan 1995; Sherr and Roberts 1995). The major mammalian $G_{1}$ cyclins include three $D$-type cyclins (D1, D2, and D3), which assemble combinatorially with CDK4 and CDK6, and cyclin E, which associates with CDK2 (Sherr 1993). Both classes of $\mathrm{G}_{1}$ cyclins are rate-limiting for $G_{1}$ progression (Ohtsubo and Roberts 1993; Quelle et al. 1993; Resnitzky et al. 1994) and contribute to the sequential phosphorylation of the retinoblastoma $(\mathrm{Rb})$ protein, thereby canceling its growth-suppressive function and facilitating entry into S-phase (Weinberg 1995; Sherr 1996). Although the activities of cyclin D-depen-

${ }^{3}$ Corresponding author.

E-MAIL sherr@stjude.org; FAX (901) 495-2381. dent kinases are not required for S phase entry in cells lacking a functional $\mathrm{Rb}$ protein (Lukas et al. 1995), inhibition of cyclin $\mathrm{E}$ function in such cells still induces $\mathrm{G}_{1}$ phase arrest (Ohtsubo et al. 1995), arguing that the cyclin E-CDK2 complex must phosphorylate substrates in addition to the $\mathrm{Rb}$ protein for DNA replication to begin. Recent work using a cell-free replication system supports the view that cyclin $\mathrm{E}-\mathrm{CDK} 2$ and $\mathrm{A}-\mathrm{CDK} 2$ can synergistically trigger the onset of DNA synthesis in HeLa cell nuclei (Krude et al. 1997).

Expression of the D-type cyclins depends on mitogenic stimulation, regardless of the position of the cell in the cycle, and growth factor withdrawal leads to rapid cyclin $\mathrm{D}$ destruction, with an associated loss of cyclin D-dependent kinase activity, accumulation of $\mathrm{Rb}$ in its hypophosphorylated forms, and $\mathrm{G}_{1}$-phase arrest (Sherr 1993). In rodent fibroblasts and macrophages where CDK4 is the dominant cyclin D-associated catalytic subunit, the CDK4 pool exceeds that of cyclin D1, enabling the cyclin to act as the rate-limiting partner in complex formation (Quelle et al. 1993; Matsushime et al. 1994). The overall 
half-life of cyclin D1 in such cells is 20-30 min, and both the free and CDK4-bound D cyclins appear to be inherently unstable; in contrast, CDK4 is a much longer lived protein $\left(t^{1} / 2=4 \mathrm{hr}\right)$ (Matsushime et al. 1992; Bates et al. 1994). Kinetic pulse-chase analyses of metabolically labeled, CDK4-bound cyclin D1 indicated previously that cyclin D1-CDK4 holoenzymes exist in a dynamic equilibrium, with the bound regulatory subunits being replaced continuously by newly synthesized cyclins (Matsushime et al. 1992). Hence, any reduction in cyclin D synthesis in cells is soon followed by a decrease in cyclin D-dependent kinase activity, and this is likely to be important in ensuring that proliferating cells arrest rapidly in $G_{1}$ phase following mitogen deprivation.

The factors that regulate the rate of cyclin $\mathrm{D}$ turnover are as yet unknown. However, degradation of the Saccharomyces cerevisiae cyclins, Clns and Clbs (Amon et al. 1994; Salama et al. 1994; Deshaies et al. 1995; Irniger et al. 1995; Seufert et al. 1995; Yaglom et al. 1995; Lanker et al. 1996), and of cyclins A, B (Glotzer et al. 1991), and E (Clurman et al. 1996; Won and Reed 1996) is mediated by ubiquitin-dependent proteolysis. In general, this process involves sequential enzymatic reactions in which ubiquitin is first charged with ATP by an activating enzyme (E1) and then is directly transferred to substrates by a ubiquitin-conjugating enzyme (E2 or UBC) or is indirectly targeted through yet additional steps involving the participation of ubiquitin ligases (so-called E3s) (Ciechanover 1994; Deshaies 1995; Jentsch and Schlenker 1995; Hilt and Wolf 1996). The resulting polyubiquinated substrates are recognized and rapidly degraded by the $26 \mathrm{~S}$ proteasome. However, when proteasomal degradation is prevented by specific inhibitory peptide aldehydes, the otherwise labile polyubiquinated intermediates can accumulate in cells until ubiquitin hydrolases and isopeptidases regenerate unconjugated substrates (Rock et al. 1994). The specificity of substrate destruction can be jointly determined by E2 and E3 selectivity, by the opposing actions of ubiquitin hydrolases (Ciechanover 1994; King et al. 1996), by recognition sequences in the substrates themselves (Rogers et al. 1986; Glotzer et al. 1991), and, in some circumstances, by substrate phosphorylation (Chen et al. 1995; Deshaies et al. 1995; Yaglom et al. 1995; Lanker et al. 1996). For example, the proteolysis of mitotic cyclin B requires E1, a specific E2, and an E3 machine, the anaphase-promoting complex (APC) or cyclosome, which consists of eight distinct polypeptides (King et al. 1995; Sudakin et al. 1995; Peters et al. 1996). Cyclin B and A degradation also require an amino-terminal "destruction box" whose removal stabilizes the protein and whose addition to other polypeptides can in turn target them for degradation (Glotzer et al. 1991).

Unlike the mitogen-dependent expression of D-type CDKs, cyclin E-CDK2 activity exhibits periodic expression, rising in late $G_{1}$ phase and declining once cells enter S phase (Dulic et al. 1992; Koff et al. 1992). This oscillatory behavior is controlled both by periodic cyclin E synthesis and degradation. Cyclin E turns over rapidly $\left(t^{1 / 2}=30 \mathrm{~min}\right)$, and although it can be stabilized in com. plexes with $\mathrm{CDK} 2$, its phosphorylation on a single threonine residue (Thr-380) allows its subsequent ubiquitination and degradation (Clurman et al. 1996; Won and Reed 1996). Cyclin E mutants containing alanine in place of Thr-380 are stabilized further when complexed to CDK2. Moreover, because the assembly of cyclin E with catalytically inactive CDK2 mutants or the blocking of wildtype CDK2 activity by CDK inhibitors prolongs the halflife of cyclin E, it was reasoned that Thr-380 phosphorylation is mediated in cis by CDK2 itself (Clurman et al. 1996; Won and Reed 1996). In this way, cyclin E may promote its own turnover by activating the enzyme that signals its destruction.

The three D-type cyclins each contain a potential proline-directed phosphorylation site (Thr-286 in cyclin D1) near their carboxyl terminus in a position superficially analogous to Thr-380 of cyclin E. We now report that cyclin D1 is phosphorylated in vivo at this site and undergoes ubiquitin-dependent proteolysis. Mutation of Thr-286 to alanine prevents this phosphorylation, inhibits polyubiquitination, and markedly stabilizes the protein. Although phosphorylation of Thr-286 is increased when cyclin D1 associates with CDK4, cyclin D1 alone or D1-containing complexes formed with catalytically inactive CDK4 mutants still undergo phosphorylation on Thr-286 when expressed in Spodoptera frugiperda Sf9 cells, implying that a kinase other than CDK4 can catalyze this modification.

\section{Results}

Proteasomal degradation of cyclin D1

To determine whether the rapid turnover of cyclin D1 is controlled by ubiquitin-mediated proteolysis, NIH-3T3 cells and 3T3-D1 derivatives engineered to overexpress cyclin D1 (Quelle et al. 1993) were treated with $N$-acetylleucinyl-leucinyl-norleucinal (LLnL), a peptide aldehyde that prevents protein degradation by inhibiting the chymotryptic site on the $26 \mathrm{~S}$ proteasome (Rock et al. 1994). LLnL treatment does not block the polyubiquitination of proteasomal substrates, thereby allowing their accumulation. However, the buildup of polyubiquitinated proteins in LLnL-treated cells is opposed by the action of de-ubiquitinating hydrolases and isopeptidases, which act to regenerate unconjugated substrates. Any further action of the isopeptidases in vitro can be inhibited by inclusion of $\mathrm{N}$-methyl-maleimide in the detergent lysis buffer. Cells treated for $16 \mathrm{hr}$ with 50 or $200 \mu \mathrm{M} \mathrm{LLnL}$ were lysed under such conditions, and proteins electrophoretically separated on denaturing polyacrylamide gels containing SDS were transferred to nitrocellulose and detected by use of a monoclonal antibody to mouse cyclin D1 (Fig. 1A). As compared to cells treated with the dimethylsulfoxide (DMSO) solvent alone (lanes 1,6$)$ or with $\mathrm{N}$-acetyl-leucinyl-leucinyl-methioninal (LLM) (lanes $4,5,9,10$ ), a structurally related calpain I inhibitor, LLnL treatment resulted in an approximate twofold increase in cyclin D1 levels (lanes $2,3,7,8$ ). Slower migrating proteins of higher molecular mass were also specifi- 
A

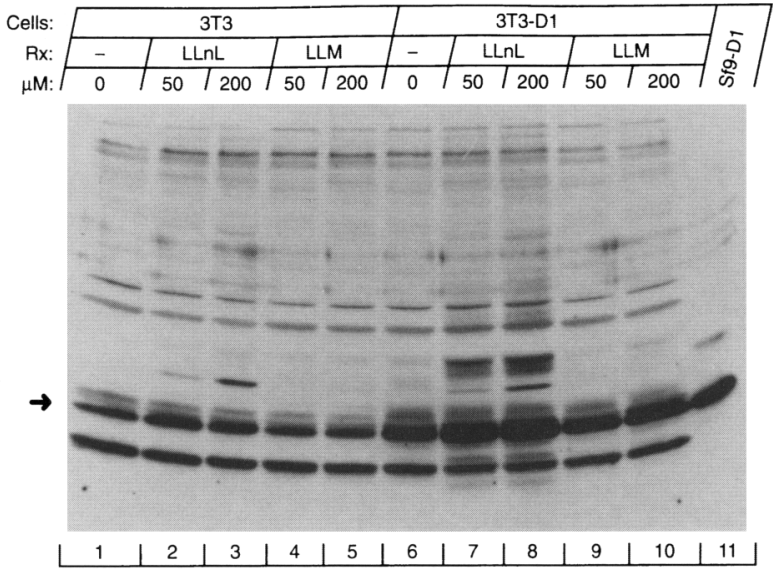

B

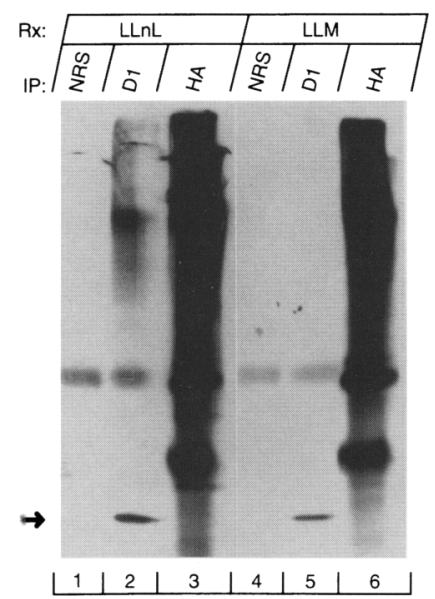

C

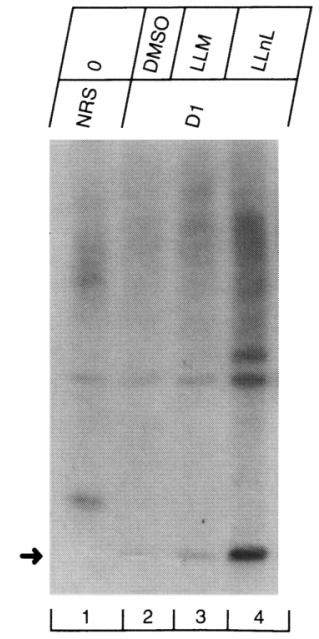

cally detected with the antibody to cyclin D1 and were most readily observed in 3T3-D1 lysates where cyclin D1 is constitutively overexpressed at levels approximately fivefold higher than those in NIH-3T3 cells (lanes $7,8)$. Therefore, cyclin Dl degradation is regulated through an LLnL-sensitive pathway.

Reasoning that the immunoreactive, higher molecular weight proteins might represent polyubiquitinated cyclin D1 species, 3T3-D1 fibroblasts were transfected with a plasmid encoding hemagglutinin (HA)-tagged ubiquitin and treated $24 \mathrm{hr}$ later with either LLnL or LLM for an additional $12 \mathrm{hr}$. Detergent lysates were precipitated with nonimmune rabbit serum or with monoclonal antibodies directed to either cyclin D1 or the HA epitope, and electrophoretically resolved proteins recovered from the denatured immunoprecipitates were immunoblotted using anti-HA to detect polyubiquitinated proteins (Fig. 1B). As expected, polyubiquitinated conjugates were directly precipitated with anti-HA from cells treated with either LLnL or LLM (lanes 3,6). Both unconjugated cyclin Dl and high molecular weight HA-ubiquitin conjugates were detected in cyclin D1 immunoprecipitates recov-

Figure 1. Ubiquitination of cyclin D1. (A) NIH-3T3 cells (lanes 1-5) or 3T3-D1 derivatives engineered to overexpress cyclin D1 (lanes 6-10) were treated for $16 \mathrm{hr}$ with DMSO solvent alone (lanes 1,6 ) or with 50 or $200 \mu \mathrm{M}$ LLnL or LLM as indicated. Detergent lysates separated electrophoretically on denaturing polyacrylamide gels were transferred to nitrocellulose and immunoblotted with a monoclonal antibody (D1-72-13G) specific for mouse cyclin D1. Sites of antibody binding were visualized by enhanced chemiluminescence. Recombinant cyclin D1 produced in Sf9 cells was used as a positive control (lane 11). The arrow indicates the mobility of nonubiquitinated cyclin D1 protein. $(B)$ 3T3-D1 cells were transfected transiently with a plasmid encoding HA-tagged ubiquitin. Twenty-four hours post-transfection, the cells were treated with either $50 \mu \mathrm{M}$ LLnL (lanes 1-3) or $50 \mu \mathrm{M}$ LLM (lanes 4-6) for $16 \mathrm{hr}$. Cell lysates normalized for protein concentration were precipitated with either normal rabbit serum (NRS; lanes 1,4), the cyclin D1 monoclonal antibody (D1, lanes 2,5), or the HA-specific monoclonal antibody 12CA5 (HA, lanes $3,6)$. Ubiquitinated proteins were visualized by immunoblotting with the antibody to HA using enhanced chemiluminescence. The arrow indicates the position of nonubiquitinated cyclin D1. (C) 3T3-D1 cells exposed for $16 \mathrm{hr}$ to DMSO (lane 2), $50 \mu \mathrm{M}$ LLM (lane 3), or $50 \mu \mathrm{M} L \mathrm{LnL}$ (lanes 1,4) were metabolically labeled with $\left[{ }^{32} \mathrm{P}\right]$ orthophosphate for the last $2 \mathrm{hr}$ of aldehyde treatment. Detergent lysates (plus $0.1 \%$ SDS) were subjected to immunoprecipitation with either normal rabbit serum (lane 1) or a rabbit antiserum specific for cyclin D1 (lanes 2-4). Phosphorylated cyclin D1 was visualized after $40 \mathrm{hr}$ of autoradiographic exposure. The arrow indicates the position of nonubiquitinated cyclin D1.

ered from cells treated with LLnL (lane 2), but only native cyclin D1 (arrow) was observed after LLM treatment (lane 5). Because no ubiquitin conjugates were detected after precipitation with control antiserum (lane 1), the results suggested that cyclin D1 was ubiquitinated.

When we attempted to directly verify this by reversing the procedure and blotting anti-HA immunoprecipitates with antibodies to cyclin D1, we detected no signal (negative data not shown). The latter result may well be attributable to technical limitations: First, following transfection with the plasmid encoding HA-ubiquitin, only a fraction of the total ubiquitin pool would be expected to be HA-tagged. Second, even under optimal conditions, only a small percentage of the $\mathrm{D} 1$ pool is stably modified after LLnL treatment (Fig. 1A, lanes 7,8). Third, the most prominent of the slower migrating forms of cyclin D1 observed after LLnL treatment (Fig. 1A) were less retarded in their mobilities on denaturing gels than the higher molecular weight HA-ubiquitin conjugates detected with anti-HA (Fig. 1B), suggesting that the antibody to HA more readily detects the most highly conjugated, polyubiquitinated species. [Similar observations 
were made in an analogous experiment using antibodies to ubiquitin itself (see Fig. 6, below)]. Nonetheless, these results leave open the possibility that a protein that coprecipitated with cyclin D1, rather than Dl itself, was polyubiquitinated. Further attempts to resolve this issue are addressed in detail below.

\section{Phosphorylation of cyclin D1 on Thr-286}

Phosphorylation of proteins can trigger their ubiquitination and degradation, as documented previously for yeast cyclins (Salama et al. 1994; Deshaies et al. 1995; Yaglom et al. 1995; King et al. 1996), for mammalian cyclin E (Clurman et al. 1996; Won and Reed 1996), and for IкB $\alpha$ (Chen et al. 1995). Multiple phosphorylated forms of cyclin D1 have been recovered from mouse macrophages and fibroblasts (Matsushime et al. 1991), and although levels of cyclin D1 in continuously proliferating cells remain elevated throughout the cell cycle, phosphorylation of cyclin D1 and the appearance of a slower migrating form of the protein on denaturing gels is markedly periodic, being maximal near the $G_{1} / S$ transition (Matsushime et al. 1991, 1994). To determine the relationship, if any, between cyclin Dl phosphorylation, ubiquitination, and degradation, 3T3-D1 fibroblasts treated with DMSO, LLM, or LLnL were metabolically labeled with $\left[{ }^{32}\right.$ P]orthophosphate, and cyclin Dl was immunoprecipitated from the lysates and resolved on denaturing gels (Fig. 1C). Cyclin D1 degradation in the lysates was minimized by collecting immune complexes in the presence of SDS. Significantly more radiolabeled cyclin D1 was immunoprecipitated from cells treated with LLnL (Fig. 1C, lane 4) than from those treated with DMSO solvent (lane 2) or LLM (lane 3). In addition, a ladder of slower migrating phosphoproteins (lane 4) comparable to the polyubiquitinated forms seen in Figure 1B (lane 2) was specifically precipitated by the $\mathrm{D} 1$ antibody, consistent with the idea that phosphorylated Dl may serve as a substrate for ubiquitin-dependent proteasomal degradation.

With the ultimate intention of interfering with cyclin D1 phosphorylation by mutagenesis, we attempted to assign the major Dl phosphorylation sites. Mammalian
3T3-D1 fibroblasts and insect Sf9 cells coinfected with baculovirus vectors encoding cyclin D1 and CDK4 were metabolically labeled with $\left[{ }^{32} \mathrm{P}\right]$ orthophosphate, and cyclin Dl recovered by immunoprecipitation was separated on denaturing gels, transferred to membranes, and digested with trypsin. The labeled phosphopeptides were then separated in two dimensions by sequential electrophoresis and chromatography (Fig. 2). Cyclin D1 isolated from mammalian fibroblasts (Fig. 2A) or from Sf9 cells coexpressing cyclin D1 and CDK4 (Fig. 2B) yielded two major phosphopeptides (labeled A and B in the fingerprints) as well as an array of minor spots that were more readily apparent on longer autoradiographic exposure (data not shown). Although it is not apparent from the experiment shown that the spots designated $A$ and $B$ in Figure 2, A and $\mathrm{B}$, are identical, mixing of the tryptic digests demonstrated that phosphopeptides $A$ and $B$ from both sources had indistinguishable mobilities in both dimensions (Fig. 2C), a result reproduced in several independent experiments. Therefore, phosphorylation of cyclin D1 in Sf9 cells coexpressing CDK4 recapitulated the key modifications observed in mammalian fibroblasts. At least half of the phosphate incorporated into cyclin D1 in both cell types was attached to serine, but phosphoamino acid analysis revealed that spots $\mathrm{A}$ and $\mathrm{B}$ contained only phosphothreonine (data not shown, but see below). Because peptides A and B were so prominent in the maps, these data together suggested that many serines in cyclin D1 were phosphorylated but in substoichiometric amounts, whereas peptides A and B contained the bulk phosphothreonine. In repeated mapping experiments, phosphopeptide $\mathrm{A}$ always predominated over phosphopeptide $B$, and in some determinations (e.g., Fig. 3, below), spot A appeared to be the only major site of threonine phosphorylation. Therefore, we suspected that phosphopeptides A and B resulted from incomplete trypsin digestion.

When Sf9 cells expressing cyclin D1 alone were labeled with $\left[{ }^{32} \mathrm{P}\right]$ orthophosphate and the radiolabeled D1 from such cells was analyzed similarly, cyclin D1 phosphorylation was reduced five- to eightfold in cells lacking CDK4, as reported previously (Kato et al. 1994). However, the tryptic phosphopeptide maps of cyclin D1 were
Figure 2. Tryptic peptide maps of phosphorylated cyclin D1. 3T3-D1 cells $\langle A|$ or $\mathrm{Sf} 9$ cells coinfected with vectors encoding cyclin Dl and CDK4 $(B)$ were labeled with $\left.{ }^{32} \mathrm{P}\right]$ orthophosphate for $2 \mathrm{hr}$. Phosphorylated cyclin DI isolated by immunoprecipitation with monoclonal antibody (D172-13G) was separated electrophoretically on denaturing polyacrylamide gels and transferred to an Immobilon-P membrane. Membrane slices containing phosphorylated cyclin D1 were digested with tryp$\sin$, and tryptic peptides were resolved by sequential electrophoresis (left to right) and ascending chromatography (bottom to top) with the origin at the lower left. (C) Results with a mixture of the two digests containing equal quantities of radioactive Dl peptides recovered from mammalian and insect cells. Peptides A and B discussed in the text are designated. The exposure times for all PhosphorImaged panels were 4 days.
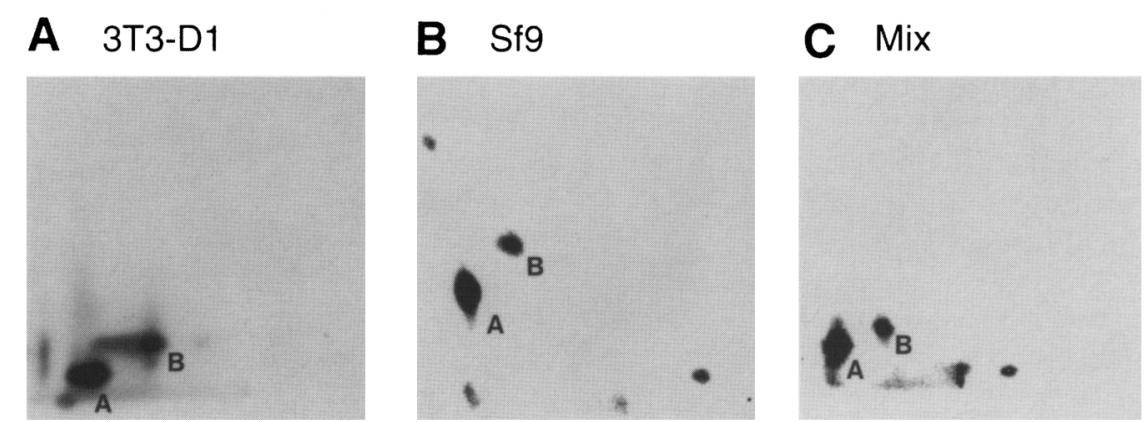
qualitatively indistinguishable from those shown in Figure $2 \mathrm{~B}$, and mixing experiments again confirmed that phosphothreonine-containing spots $\mathrm{A}$ and $\mathrm{B}$ were the predominant species (data not shown). Therefore, phosphorylation of mouse cyclin Dl on threonine in insect Sf9 cells appeared not to depend upon assembly with, or autophosphorylation by, CDK4, although it could in principle have been catalyzed by an endogenous insect CDK.

When complexed to its catalytic partner CDK2, cyclin E is autophosphorylated on Thr-380, and mutation of this single threonyl residue to alanine stabilizes the complex and prevents ubiquitin-dependent cyclin E proteolysis (Clurman et al. 1996; Won and Reed 1996). Alignment of cyclin $\mathrm{E}$ with the D-type cyclins reveals that Thr-286 in cyclin D1, as well as Thr-280 in D2 and Thr-283 in D3, is loosely conserved in amino acid sequence context and in its proximity to the carboxyl termini. Based on these results, we converted serine and threonine residues in several potential cyclin D1 CDK phosphorylation sites (Ser-Pro and Thr-Pro) to alanine, Thr-286 among them. Mutated and wild-type D1 cDNAs were tagged at their $5^{\prime}$ ends with sequences encoding a Flag epitope so that they could be recovered with M2 monoclonal antibodies to the Flag-tag and distinguished from endogenously expressed D1 molecules.

Sf9 cells were infected with baculovirus vectors encoding CDK4 together with either Flag-tagged wild-type or mutant D1 proteins. Mapping of phosphotryptic peptides derived from $\left[{ }^{32} \mathrm{P}\right]$ orthophosphate-labeled cyclins indicated that peptides A and B were completely absent from the T286A mutant (Fig. 3, cf. A and B; as noted above, peptide A was more prominent in this experiment). Residues carboxy-terminal to Thr-286 in cyclin D1 include a single basic amino acid (Arg-291), which is immediately followed by acidic residues (Asp-Val-Asp-Ile-COOH). A failure of trypsin to completely cleave the protein at Arg291 could therefore yield two peptides containing Thr286 in varying quantities. Alternatively, the T286A mutation could have changed the conformation of cyclin D1 in such a way as to affect phosphorylation at other sites. To distinguish between these possibilities, Thr-286 was converted to serine, and after coexpression of the mutant cyclin in Sf9 cells with CDK4, phosphopeptides derived from the T286S mutant were mapped. Figure $3 \mathrm{C}$ reveals that although spot $\mathrm{A}^{\prime}$ (with a mobility virtually identical to spot $\mathrm{A}$ in Fig. 3A by mixing) represented the major site of cyclin D1 phosphorylation, the T286S mutant contained only phosphoserine (Fig. 3C, inset). Therefore, we deduced that Thr-286 is the major site of cyclin D1 phosphorylation, both in Sf9 cells (Fig. 3) and in mammalian fibroblasts (Fig. 2).

\section{Cyclin D1 (T286A) binds and activates CDK4}

We next introduced Flag-Dl and Flag-D1 (T286A) cDNAs into a mammalian expression vector and tested the ability of each tagged protein to productively assemble with CDK4 in transiently transfected NIH-3T3 cells. Detergent lysates prepared $48 \mathrm{hr}$ post-transfection were subjected to immunoprecipitation with either nonimmune rabbit serum, antiserum to CDK4, or with the M2 monoclonal antibody to the Flag epitope. The precipitated proteins were denatured, separated on gels, and immunoblotted with antibody to cyclin D1 (Fig. 4A). Whereas control nonimmune serum precipitated no cyclin D1 (lanes 1,4), the antiserum to CDK4 precipitated two cyclin D1 species (lanes 2,5), corresponding in mobility to endogenous cyclin D1 (lane 7) and the Flagtagged form (lane 8). As expected, only the ectopically expressed Flag-tagged form of D1 (denoted as D1 * in this and subsequent figures) was precipitated with the M2 antibody (lanes 3,6). Much of the Flag-tagged D1 species coprecipitated with CDK4 (cf. lanes 2 vs. 3 and lanes 5 vs. 6), whether D1 was wild type or mutated at Thr-286. Therefore, neither the Flag-tag nor the T286A mutation prevented assembly of exogenous D1 with CDK4 in vivo.

Lysates from Sf9 cells coinfected with baculoviruses encoding CDK4 and wild-type or mutant Flag-D1 were tested for $\mathrm{Rb}$ protein kinase activity (Fig. 4B). Although lysates containing CDK4 alone were devoid of activity (lane 1), those coexpressing Flag-D1 (lane 2) or the T286A and T286S mutants (lanes 3 and 4, respectively) contained readily detected kinases. Controls confirmed that similar quantities of cyclin D1-CDK4 complexes were immunoprecipitated from these lysates and that
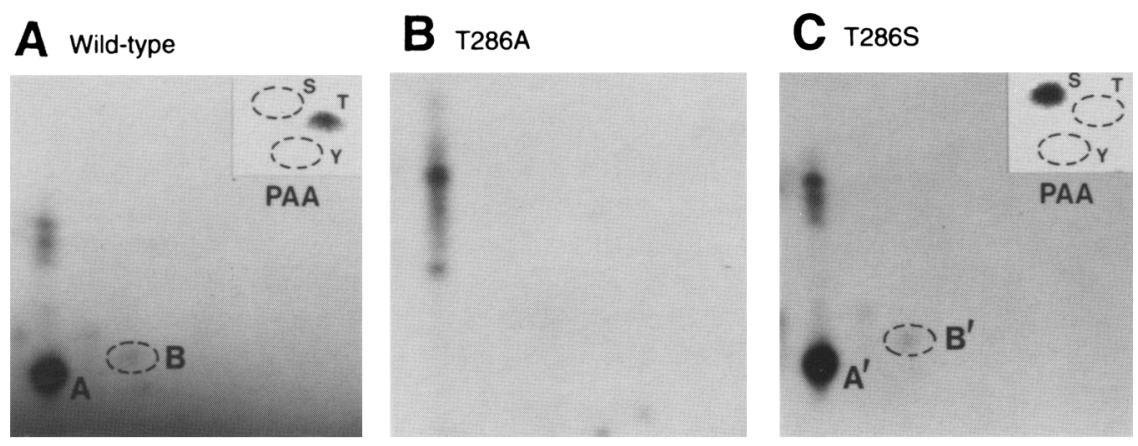

Figure 3. Tryptic peptide maps of mutant cyclin D1 phosphoproteins. Sf9 cells coinfected with CDK4 and wild type, Flagtagged cyclin D1 $(A)$, Flag-tagged mutant cyclin D1 T286A $(B)$, or Flag-tagged mutant cyclin D1 T286S $(C)$ were labeled with $\left[{ }^{32} \mathrm{P}\right]$ orthophosphate for $2 \mathrm{hr}$. Flagtagged D1 proteins recovered by immunoprecipitation with monoclonal antibodies were processed for two-dimensional tryptic mapping as in Fig. 2. Autoradiographic exposure times were 6 days. The insets in $A$ and $C$ show phosphoamino acid analyses of phosphopeptides A and A', respectively. Peptides eluted from the thin layer chromatography plates were hydrolyzed in acid, and phosphoamino acids were separated electrophoretically in two dimensions. The positions of internal standards $[(\mathrm{S})$ serine; $(\mathrm{T})$ threonine; (Y) tyrosine] visualized with ninhydrin are indicated. Exposure times for the PhosphorImaged amino acids were 4 days. 


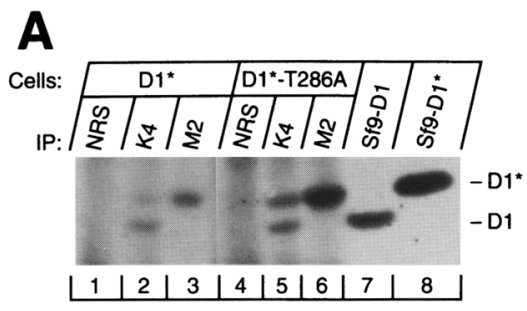

B

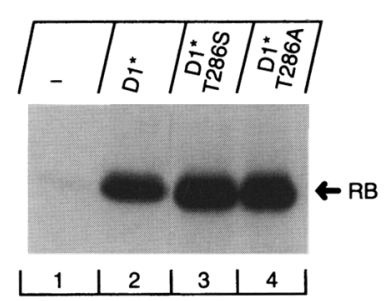

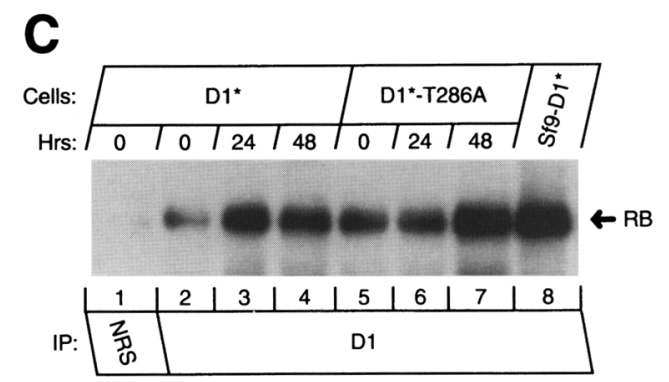

Figure 4. Assembly of Flag-tagged cyclin D1-CDK4 complexes and Rb protein kinase activity. (A) NIH-3T3 cells were transfected with expression vectors encoding CDK4 and Flag-tagged D1 (lanes 1-3) or CDK4 and the Flag-tagged D1 T286A mutant (lanes 4-6). Forty-eight hours post-transfection, detergent lysates normalized for protein concentration were subjected to immunoprecipitation with normal rabbit serum (lanes 1,4), CDK4-specific rabbit serum $\left(R_{z}\right.$, lanes 2,5), or the $M 2$ monoclonal antibody to the Flag epitope (lanes 3,6$)$. Immune complexes were separated electrophoretically on denaturing polyacrylamide gels, transferred to nitrocellulose, immunoblotted with cyclin D1 monoclonal antibody (D1-72-13G), and visualized by enhanced chemiluminescence. Flag-tagged cyclin D1 (lane 8) and untagged cyclin D1 (lane 7) expressed in Sf9 cells were run as markers, and their mobilities are designated in the right margin as D1* and D1, respectively. (B) Lysates were prepared from uninfected Sf 9 cells (lane 1) or from Sf 9 cells coinfected with baculoviruses encoding CDK4 and the indicated Flag-tagged D1 proteins (lanes 2-4), and the levels of expression of Flag-tagged D1 proteins were normalized by immunoblot analysis (data not shown). Lysates containing equal quantities of Flag-D1 protein were assayed for Rb kinase activity, and the labeled GST-Rb protein products (indicated by the arrow) were resolved on denaturing polyacrylamide gels (exposure time, $12 \mathrm{~min}$ ). (C) NIH-3T3 cells expressing Flag-tagged D1 (lanes 1-4) or the Flag-tagged D1 T286A mutant (lanes 5-7) under the control of the zinc-inducible sheep metallothionein promoter were induced with $80 \mu \mathrm{M} \mathrm{ZnSO}_{4}$ for the indicated periods of time (hr). Cyclin D1 immune complexes prepared with monoclonal antibody D1-72-13G were assayed for Rb protein kinase activity. As a positive control, a cyclin D1 immune complex prepared from an Sf9 lysate containing CDK4 and Flag-tagged cyclin D1 was assayed in parallel (lane 8). Autoradiographic exposure time was $2 \mathrm{hr}$.

the recovered immune complexes also supported $\mathrm{Rb}$ protein kinase activity (data not shown).

To ensure that Flag-D1 mutants assembled with CDK4 to yield active kinases in mammalian cells, we derived NIH-3T3 cell lines expressing Flag-Dl or FlagD1 (T286A) under the control of a zinc-inducible sheep metallothionein promoter. Preliminary dose-response experiments indicated that tagged D1 proteins were maximally induced when $80 \mu \mathrm{M}$ zinc sulfate was added to the culture medium. Induction of the proteins under these conditions was readily observed after $3 \mathrm{hr}$ of zinc treatment and, in the case of the wild-type protein, was maximal after $5 \mathrm{hr}$; in contrast, the Flag-D1 (T286A) protein continued to accumulate to levels about twofold higher than the wild-type protein over a period of $48 \mathrm{hr}$ (data not shown), possibly reflecting differences in protein turnover (see below). Lysates from cells treated with zinc for 24 or $48 \mathrm{hr}$ were normalized for total protein and precipitated with an antibody to cyclin Dl that supports kinase activity in immune complexes (Fig. 4C). Cyclin $\mathrm{D} 1$-dependent $\mathrm{Rb}$ protein kinase activity was recovered from uninduced cells ectopically expressing the wildtype Flag-Dl protein (lane 2). A substantial increase in $\mathrm{Rb}$ protein kinase activity in these cells was detected 24 $\mathrm{hr}$ after zinc induction (lane 3) with no further increase after $48 \mathrm{hr}$ of treatment (lane 4). Uninduced cells expressing mutant Flag-D1 (T286A) exhibited more Rb protein kinase activity (lane 5) than that detected in cells ectopically expressing the wild-type protein (lane 2). Further induction of enzyme activity was observed after $48 \mathrm{hr}$ of zinc treatment (lane 7) and achieved levels somewhat greater than those in zinc-induced cells expressing the wild-type Flag-D1 protein (lanes 3,4). The levels of kinase activity recovered in the zinc-induced cell lines approached those detected in 3T3-D1 fibroblasts that stably overexpress cyclin D1 (Matsushime et al. 1994) and that exhibit a contracted $G_{1}$ phase when stimulated by serum (Quelle et al. 1993). Because of partial toxicity of zinc sulfate treatment, we were unable to compare the rates of $G_{1}$ progression in cells expressing Flag-tagged wild-type and mutant $\mathrm{D} 1$ molecules, although their cell cycle distributions were not markedly different over the course of a 48-hr induction period. The key conclusion here is that mutation of Thr-286 to alanine does not affect the ability of cyclin D1 to activate CDK4 in Sf9 cells (Fig. 4B) or in mammalian fibroblasts (Fig. 4C). The results also suggested that the T286A mutant accumulated to somewhat higher levels than the wild-type D1 protein (Fig. 4A,C).

\section{Mutation of Thr-286 to alanine stabilizes cyclin D1}

To determine whether phosphorylation of Thr-286 affects cyclin D1 turnover, cells expressing Flag-D1 or Flag-D1 (T286A) were induced for $16 \mathrm{hr}$ with zinc and then pulse-labeled metabolically with $\left[{ }^{35} \mathrm{~S}\right]$ methionine for $30 \mathrm{~min}$. Labeled methionine was removed from the medium, and cells were "chased" in the presence of a 100 -fold excess of unlabeled methionine for $2 \mathrm{hr}$. Cell lysates prepared after different periods of chase were precipitated with the M2 monoclonal antibody, and the labeled proteins were resolved on denaturing gels (Fig. 5A). The half-life of Flag-tagged D1 was calculated to be $\sim 30$ min (lanes 2-6), whereas that of the T286A mutant ex- 

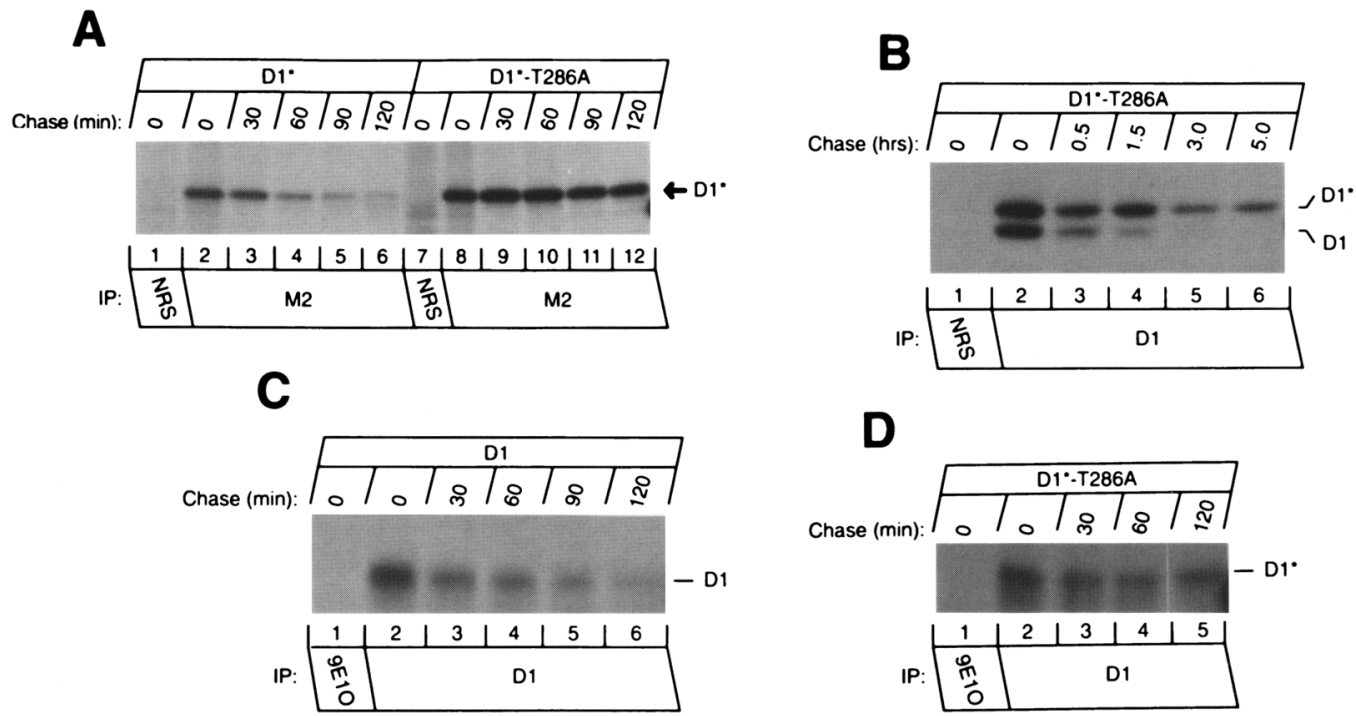

Figure 5. Kinetics of cyclin D1 protein turnover. (A) After induction of wild type Flag-tagged cyclin D1 (lanes 1-6) or Flag-tagged cyclin D1 T286A (lanes 7-12) with $80 \mu \mathrm{MnSO}_{4}$ for $16 \mathrm{hr}$, cells were metabolically labeled with $\left[{ }^{35}\right.$ S $]$ methionine for $30 \mathrm{~min}$. Washed cells refed with complete medium containing excess unlabeled methionine were collected at the indicated times and precipitated with normal rabbit serum (lanes 1,7) or with the M2 monoclonal antibody to the Flag epitope (lanes 2-6, 8-12), as indicated below the panel. Cyclin Dl proteins were resolved on denaturing polyacrylamide gels and visualized by fluoroautoradiography (exposure time $12 \mathrm{hr}$ ). (B) After induction of Flag-tagged D1 T286A expression with $80 \mu \mathrm{MnSO}_{4}$ for $16 \mathrm{hr}$, cells were processed as in $A$ and subjected to immunoprecipitation with normal rabbit serum (lane 1) or with monoclonal antibody to cyclin D1 (lanes 2-6). Cyclin D1 proteins visualized by fluoroautoradiography (exposure time, $16 \mathrm{hr}$ ) included the ectopic flag-tagged species $\left(\mathrm{Dl}{ }^{*}\right.$ ) and the endogenous mouse cyclin (D1), as indicated at right. (C) 3T3-Dl cells engineered to overexpress untagged cyclin D1 were arrested in $\mathrm{G}_{0}$ by serum starvation $\mid<1 \% \mathrm{~S}$ phase) and were metabolically labeled for 30 min with $\left[{ }^{35} \mathrm{~S}\right]$ methionine in medium lacking FCS. Cells washed and refed with medium containing excess unlabeled methionine but lacking FCS were collected at the indicated times, processed as in $A$, and precipitated with an irrelevant monoclonal antibody $(9 \mathrm{E} 10)$ or with antibody to cyclin D1, as indicated below (fluoroautoradiography exposure time, $20 \mathrm{hr}$. $(D)$ NIH-3T3 cells expressing zinc-inducible Flag-tagged D1 T286A were arrested in $\mathrm{G}_{0}$ by serum starvation. After induction of Flag-tagged D1 T286A expression with $80 \mu \mathrm{M} \mathrm{ZnSO}_{4}$ for $60 \mathrm{~min}$, cells were metabolically labeled with $\left[{ }^{35} \mathrm{~S}\right]$ methionine for $30 \mathrm{~min}$ in medium containing $80 \mu \mathrm{M} \mathrm{ZnSO}$, but lacking FCS. Cells were processed as in C, and cyclin D1* was visualized by fluoroautoradiography (exposure time 6 days). Induction times were kept to a minimum to avoid zinc toxicity in the absence of FCS.

ceeded $2 \mathrm{hr}$ (lanes 8-12). A second experiment was performed in which the chase period was extended, but here, the lysates were immunoprecipitated with an antibody to cyclin D1 (Fig. 5B). Because of their different electrophoretic mobilities on denaturing gels, we could compare the turnover of endogenous cyclin D1 with that of the ectopically expressed Flag-D1 (T286A) protein recovered from the same cell lysates. Note that after $16 \mathrm{hr}$ of zinc treatment, the rate of synthesis of Flag-D1 (T286A) (the slower migrating species) was comparable to that of the endogenous cyclin D1 protein (the faster form) (Fig. 5B, lane 2). However, the half-life of endogenous Dl was $\sim 30 \mathrm{~min}$, whereas that of the T286A mutant was $3.5 \mathrm{hr}$, as calculated by densitometric measurements from several such experiments.

Although much of the ectopically expressed cyclin D1 in proliferating NIH-3T3 cells is complexed to CDK4 (Fig. 4A,C), ectopically coexpressed CDK4 and D-type cyclins cannot assemble into binary complexes when such cells are deprived of growth factors and enter $G_{0}$ (Matsushime et al. 1994). In 3T3-D1 overexpressors rendered quiescent by starvation for $48 \mathrm{hr}$ in medium con- taining $0.1 \%$ serum, the half-life of the ectopically expressed cyclin D1 remained short ( $t 1 / 2 \sim 30 \mathrm{~min})$ (Fig. $5 \mathrm{C})$. However, when quiescent cells transfected with the inducible T286A mutant were treated with zinc and then pulse labeled, the Flag-tagged D1 (T286A) protein was again stabilized $\left(t^{1 / 2}>2 \mathrm{hr}\right)$ (Fig. $\left.5 \mathrm{D}\right)$. The wild-type, but not mutant, D1 proteins were phosphorylated, and as expected, neither the wild-type nor mutant Dl proteins recovered from serum-starved cells coprecipitated with CDK4 (data not shown). Therefore, cyclin D1 is phosphorylated and intrinsically unstable even when unbound to CDK4, whereas under similar conditions, the T286A mutant is protected from degradation. The results also imply that a kinase other than CDK4 can phosphorylate cyclin D1 on Thr-286 in mammalian cells.

If phosphorylation at Thr-286 regulates cyclin Dl ubiquitination, stabilization of Flag-D1 (T286A) should reflect its reduced ubiquitination relative to Flag-D1. Therefore, Flag-D1 or the Flag-D1 (T286A) mutant was induced by zinc treatment for $22 \mathrm{hr}$, and the cells were treated with LLnL or LLM during the last $16 \mathrm{hr}$ of zinc induction. Cyclin D1 precipitated from cell lysates with 
antibody M2 to the Flag epitope was separated on denaturing gels, and polyubiquitinated proteins in the immune complexes were detected by blotting with a ubiquitin-specific monoclonal antibody (Fig. 6, top). Consistent with results obtained with HA-tagged ubiquitin (Fig. 1B), high molecular weight ubiquitin conjugates were specifically precipitated with the M2 antibody from LLnL-treated cells expressing wild-type Flag-D1 (cf. lane 3 and lane 1), but not from cells treated with LLM (lane 2 ). In contrast, no polyubiquitinated proteins were recovered from LLnL-treated cells expressing Flag-D1 (T286A) (lanes 4-6). To verify that the latter result was not attributable to reduced expression of the mutant D1 protein, the membrane was stripped and reblotted with monoclonal antibody to cyclin Dl (Fig. 6, bottom). As noted above, the accumulation of Flag-D1 (T286A) (lanes 5,6) exceeded that of wild-type Flag-D1 (lanes 2,3),

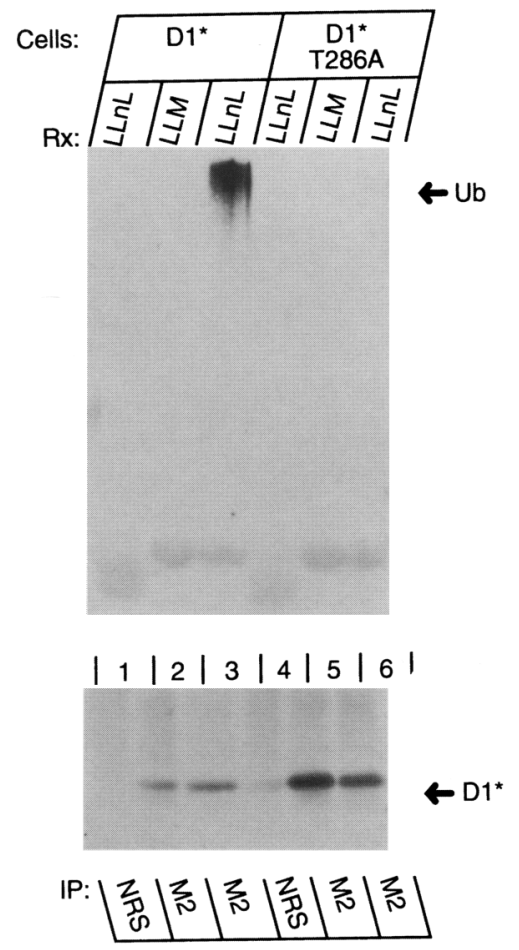

Figure 6. Cyclin D1 (T286A) is not a substrate for ubiquitination. Flag-tagged D1 (lanes 1-3) or Flag-tagged D1 T286A (lanes 4-6) were induced with $\mathrm{ZnSO}_{4}$ for $22 \mathrm{hr}$. During the last $16 \mathrm{hr}$ of induction, $50 \mu \mathrm{M}$ LLM or $50 \mu \mathrm{M}$ LLnL was added to the medium, as indicated $(\mathrm{Rx})$ at the top. Cell lysates normalized for protein concentration were subjected to immunoprecipitation with either normal rabbit serum (lanes 1,4) or the M2 monoclonal antibody to the Flag epitope (lanes $2,4,5,6)$ as indicated below. Immune complexes were separated electrophoretically on denaturing polyacrylamide gels followed by transfer to nitrocellulose. Flag-tagged D1 proteins were visualized by immunoblotting with the D1 monoclonal antibody (bottom). Subsequently, the membrane was stripped and reprobed with an anti-ubiquitin monoclonal antibody (top). Proteins were visualized by enhanced chemiluminescence. The arrow at right $\{$ top $\rangle$ indicates the position of polyubiquitinated conjugates (Ub). regardless of whether the cells were treated with LLnL or LLM. Therefore, the T286A mutation prevented the polyubiquitination of cyclin Dl itself and/or of proteins specifically coprecipitating with it. In addition, this experiment implies that CDK4 is not the major polyubiquitinated species in cyclin D1 immunoprecipitates, as the catalytic subunit forms active holoenzyme complexes with Flag-D1 (T286A) (Fig. 4).

Next we attempted to reconstitute the ubiquitination system in vitro. Sf9 lysates coexpressing phosphorylated cyclin D1 and CDK4 (Figs. 2 and 3) were mixed on ice with separately prepared Sf9 lysates programmed to express HA-ubiquitin. Following addition of ATP, lysates were incubated at $37^{\circ} \mathrm{C}$ for various times and then diluted at $4{ }^{\circ} \mathrm{C}$ into RIPA buffer containing $0.1 \%$ SDS. Cyclin D1 was precipitated with monoclonal antibody, separated on denaturing gels, and blotted with antibodies to the HA epitope. Dl immunoprecipitates from these reactions yielded polyubiquitinated proteins in a timedependent (Fig. 7, A and C, lanes 2-4, and lanes 2-6, respectively) and an ATP-dependent (Fig. 7C, lane 1) manner. No such proteins were identified in immunoprecipitates from reactions lacking either HA-ubiquitin (Fig. 7A, lane 1) or cyclin D1 (lane 5).

To determine whether cyclin D1 was ubiquitinated in these reactions, mixtures incubated for $30 \mathrm{~min}$ in the presence of ATP were boiled in SDS prior to precipitation with the D1 monoclonal antibody, and the resulting immunoprecipitates were separated on gels and blotted with antibody to HA (Fig. 7B). Polyubiquitinated species were detected in D1 immunoprecipitates recovered from both boiled (lane 2) and unboiled (lane 3) lysates but not in precipitates prepared using control antibody (lane 1). This result argues that ubiquitin was linked covalently to cyclin D1. Moreover, when anti-HA precipitates from the unboiled in vitro reaction mixtures were blotted with antibody to D1, high molecular weight forms of D1 were readily detected (Fig. 7B, lane 5), whereas no such forms of D1 were seen in control precipitates (lane 4). Finally, although immunoprecipitates recovered from lysates programmed with wild-type D1 yielded polyubiquitinated proteins (Fig. 7C, lanes 2-6), those programmed with the D1 (T286A) mutant did not (lanes 7-11). Therefore, cyclin D1 is a substrate for polyubiquitination, and its modification in vitro depends upon the integrity of Thr-286.

\section{Thr-286 phosphorylation depends on CDK4 assembly but not on CDK4 kinase activity}

Thr-286 is flanked by an amino-terminal prolyl residue but lacks a proximal carboxy-terminal basic amino acid characteristic of canonical CDK phosphorylation sites (T/S-P-X-K/R). However, cyclin D-CDK4 complexes can phosphorylate minimal SP and TP CDK motifs, albeit with reduced efficiency (Hirai and Sherr 1996; Kitagawa et al. 1996), suggesting that Thr-286 might be phosphorylated as a consequence of D1-CDK4 assembly and activation. To test whether Thr-286 phosphorylation depends on CDK4 kinase activity, we infected Sf9 

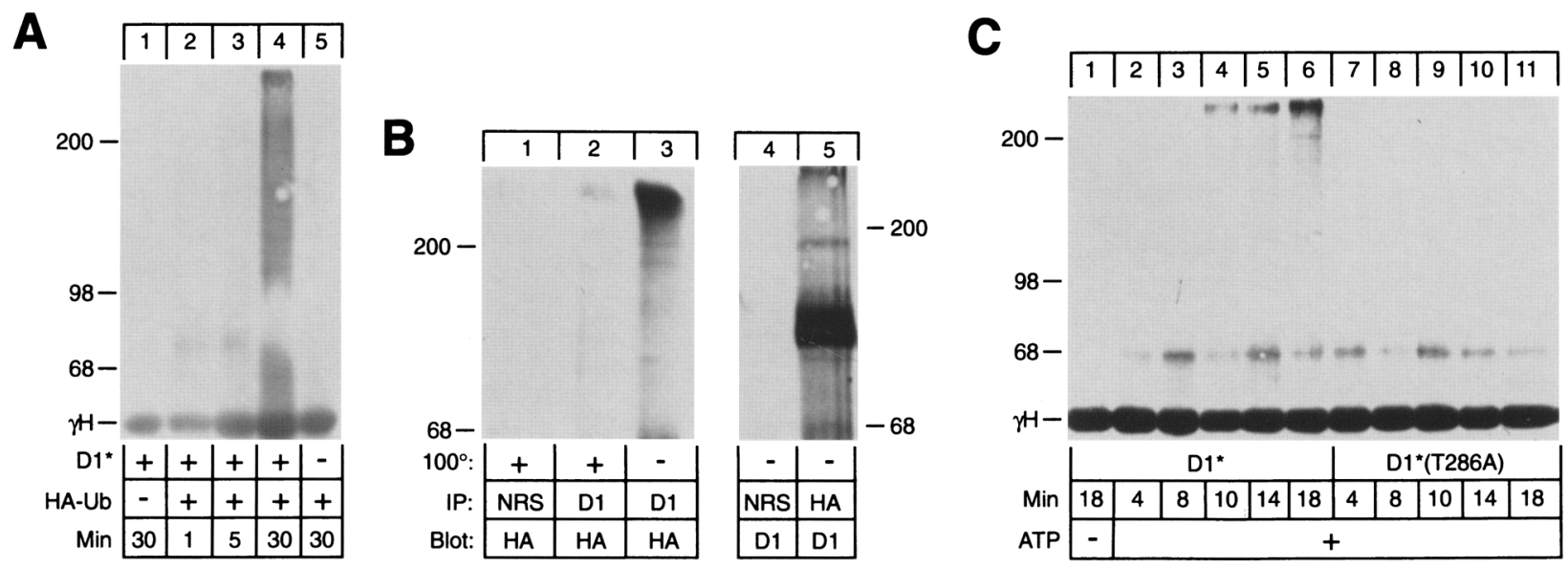

Figure 7. Ubiquitination of cyclin D1 in vitro. (A) Sf9 lysates containing Flag-tagged D1 (D1*) in complexes with CDK4 were mixed with lysates containing HA-ubiquitin (HA-Ub) and ATP and incubated at $37^{\circ} \mathrm{C}$ for the indicated times (min). Proteins precipitated with monoclonal antibody to D1 were separated on gels and blotted with anti-HA. (B) Reactions as in $A$ were incubated for 30 min. (Lanes 1-3) Two-thirds of the reaction mixture $\{80 \mu \mathrm{l})$ was boiled in SDS-containing buffer $\left(100^{\circ} \mathrm{C}\right)$, divided in half, and precipitated with nonimmune rabbit serum (NRS, lane 1 ) or antibody to D1 (lane 2). One-third of the unboiled lysate (40 $\mu 1)$ was directly precipitated with anti-D1 (lane 3). Precipitates separated on gels were blotted with anti-HA. Another reaction mixture (80 $\mu$ ) was divided in half and precipitated with control serum (lane 4) or anti-HA (lane 5), and the separated proteins were blotted with anti-D1. (C) Sf9 lysates containing wild-type, Flag-tagged cyclin D1 (D1*) and CDK4 (lanes 1-6) or cyclin D1* (T286A) and CDK4 (lanes 7-11) were incubated with lysates containing HA-ubiquitin for the indicated times. Lane 1 shows a control incubation to which EDTA rather than ATP was added. Proteins were precipitated with anti-D1 and blotted with anti-HA. The electrophoretic mobilities of molecular weight markers $(\mathrm{kD})$ and immunoglobulin heavy chains $(\gamma \mathrm{H})$ are indicated. Proteins were detected by enhanced chemiluminescence (1-min exposure).

cells with a baculovirus encoding Flag-D1 either alone, together with wild-type CDK4, or together with either of two catalytically inactive CDK4 mutants that retain the ability to assemble into complexes with D-type cyclins. CDK4 (T172) lacks the single T-loop phosphorylation site recognized by the CDK-activating kinase (CAK) but is still phosphorylated on serine residues; CDK4 (K35M) is missing a lysyl residue that coordinates ATP binding, and it undergoes phosphorylation on both Thr-172 and serine residues (Kato et al. 1994). Hence, wild-type cyclin D1 as well as the wild-type and mutant CDK4 molecules can all be labeled with $\left[{ }^{32} \mathrm{P}\right]$ orthophosphate when coexpressed in Sf9 cells.

Lysates of coinfected Sf9 cells metabolically labeled with $\left[{ }^{32} \mathrm{P}\right]$ orthophosphate were precipitated with control nonimmune serum or with a monoclonal antibody to cyclin D1 (Fig. 8A). As indicated above, cyclin D1 was phosphorylated (on Thr-286) even in cells that did not express CDK4 (lane 2), but a five- to eightfold stimulation of cyclin D1 phosphorylation was seen in cells coinfected with CDK4 (lane 4), which was itself phosphorylated as expected (lane 5) (Kato et al. 1994). CDK4 coprecipitated with antibodies to cyclin D1 (lane 4); however, the antibodies directed to full-length CDK4 $\left(\mathrm{R}_{\mathrm{Y}}\right)$ do not efficiently recognize these complexes (lane 5) despite their ability to readily precipitate the unbound catalytic subunits (Matsushime et al. 1994). Importantly, the increase in cyclin D1 phosphorylation observed in cells expressing wild-type CDK4 was also seen in cells coexpressing the catalytically inactive $\mathrm{CDK}$ mutants, both of which assembled into cyclin D1-CDK complexes (lanes 7,10).
To confirm that complexes composed of Flag-Dl and mutant CDK4 proteins were inactive, we assayed the ability of complexes precipitated with anti-Flag to phosphorylate $\mathrm{Rb}$ protein (Fig. $8 \mathrm{~B}$ ); as expected, wild-type CDK 4 yielded $\mathrm{Rb}$ protein kinase activity (lane 2, top), but the mutants did not (lanes 3,4). As opposed to the anti-CDK4 serum used in the experiment shown in Figure 8A, CDK4 immunoprecipitates from the same cells were prepared using an antiserum to the CDK4 carboxyl terminus $\left(\mathrm{R}_{\mathrm{z}}\right)$, which precipitates Dl-CDK complexes (Matsushime et al. 1994). When the precipitated proteins were blotted with anti-D1, no Flag-D1 coprecipitated with anti-CDK4 from lysates containing FlagD1 alone (Fig. 8B, lane 1, bottom), but complexes between Flag-D1 and CDK4 were observed in cells coexpressing either wild-type or mutant CDK4 (lanes 2-4, bottom), confirming the results obtained with antibodies to D1 (Fig. 8A).

Finally, we analyzed the sites of cyclin D1 phosphorylation in $\mathrm{Sf} 9$ cells coexpressing untagged cyclin D1 together with the different CDK4 mutants. Thr-286-containing phosphopeptides $\mathrm{A}$ and $\mathrm{B}$ were recovered from cyclin D1, whether it was coexpressed with wild-type CDK4 (Fig. 8C, left) or with the two catalytically inactive mutant forms (Fig. 8C, middle and right). We conclude that phosphorylation of Thr-286 in cyclin D1 is increased when it assembles with CDK4, regardless of whether CDK4 is catalytically active or not. Although these results do not preclude the possibility that wildtype CDK4 can phosphorylate cyclin D1 in such complexes, the fact that phosphorylation proceeds as efficiently in Sf9 cells coexpressing catalytically inactive 
Diehl et al.

A

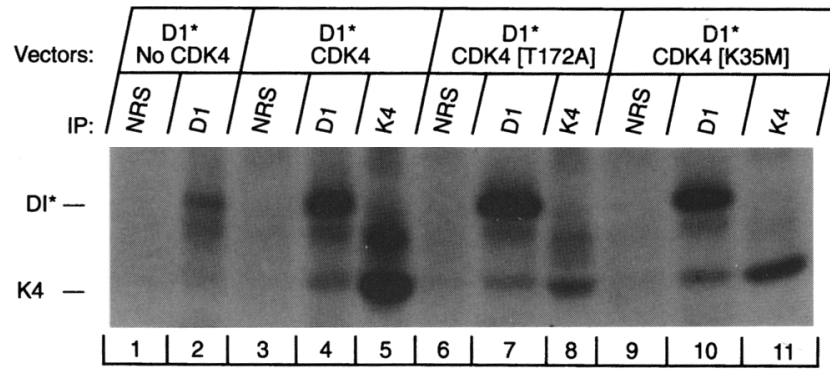

C
D1 + CDK4

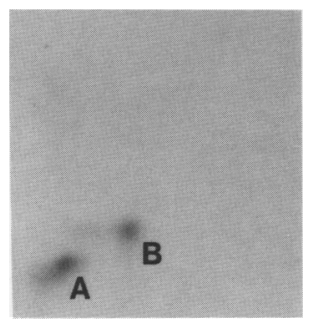

$\mathrm{D} 1+\mathrm{K} 4[\mathrm{~T} 172 \mathrm{~A}]$

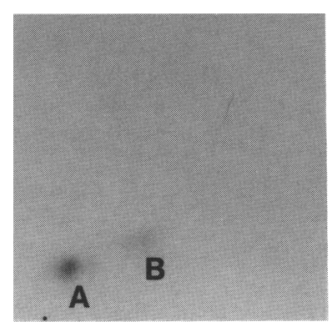

B

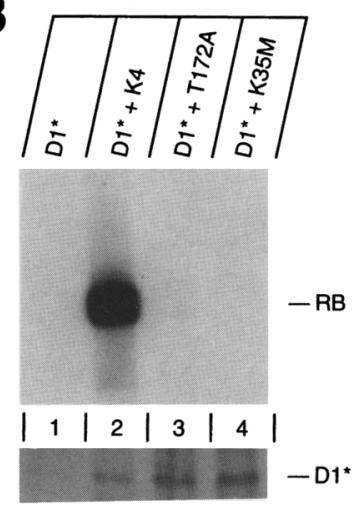

$\mathrm{D} 1+\mathrm{K} 4[\mathrm{~K} 35 \mathrm{M}]$

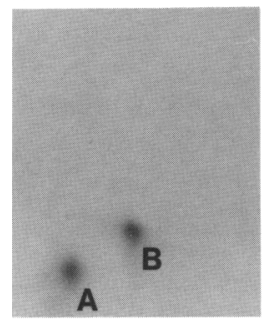

Figure 8. Threonine-286 phosphorylation in Sf9 cells does not require CDK4 activity. $(A)$ Sf9 cells infected with Flag-tagged D1 or coinfected with Flag-tagged D1 plus either wild-type CDK4 (lanes 3-5), CDK4 (T172A) (lanes 6-8), or CDK4 (K35M) were labeled with $\left[{ }^{32} \mathrm{P}\right]$ orthophosphate for $2 \mathrm{hr}$. Cell lysates were precipitated with monoclonal antibody to cyclin $\mathrm{D} 1$ or with rabbit antiserum $\left(\mathrm{R}_{\mathrm{Y}}\right)$ to CDK4 as indicated at the top, and immune complexes were separated electrophoretically on denaturing polyacrylamide gels and transferred to an Immobilon-P membrane (autoradiographic exposure time $50 \mathrm{hr}$ ). The positions of Flag-D1 (D1 *) and CDK4 (K4) are indicated at left. (B) Flag-tagged D1-CDK4 complexes were isolated from the lysates described in $A$ by immunoprecipitation with monoclonal antibody to cyclin D1, and immune complexes were assayed for Rb protein kinase activity (top). Products were separated electrophoretically on denaturing polyacrylamide gels and visualized by autoradiography (exposure time, $15 \mathrm{~min}$ ). The same lysates were precipitated with antiserum to CDK4 $\left(R_{z}\right)$, and coprecipitating Flag-tagged cyclin D1 was visualized by immunoblotting with the monoclonal antibody to cyclin D1 and enhanced chemiluminescence (bottom). (C) Sf 9 cells coinfected with baculovirus vectors encoding (untagged) cyclin Dl and CDK4, cyclin Dl and CDK4 (T172A), or cyclin D1 and CDK4 (K35M) were labeled with [ $\left.{ }^{32} \mathrm{P}\right]$ orthophosphate for $2 \mathrm{hr}$. Cells were lysed in the presence of SDS, and immune complexes containing the labeled D1 protein were separated electrophoretically on denaturing polyacrylamide gels and transferred to Immobilon-P membranes. Strips containing cyclin D1 were directly digested with trypsin, and the resulting phosphopeptides were analyzed as described in Fig. 2. Autoradiographic exposure times were 10 days.

CDK4 subunits strongly argues that Thr-286 can be phosphorylated by another enzyme.

\section{Discussion}

\section{Cyclin D1 is phosphorylated at Thr-286}

The synthesis of cyclin D1 and its assembly with CDK4 depend on mitogenic signaling. Growth factor withdrawal precludes formation of new cyclin D1-CDK4 complexes, and the inherent instability of cyclin Dl ensures the rapid decay of preexisting holoenzyme activity as cells exit the cycle. In proliferating mouse macrophages, two major phosphorylated forms of cyclin D1 that were detected previously were distinguished by their electrophoretic mobilities on denaturing polyacrylamide gels. Cyclin D1 is synthesized throughout the macrophage cell cycle as long as colony-stimulating factor-1 (CSF-1) stimulation continues, but the appearance of the slowly migrating phosphorylated species is highly periodic and maximal near the $G_{1} / S$ transition (Matsushime et al. 1991). Its accumulation temporally correlates with the assembly of cyclin D1-CDK4 complexes and with their concomitant activation in mid- to late $G_{1}$ phase (Matsushime et al. 1994) and its disappearance with the loss of cyclin D1 immunostaining in nuclei and accelerated D1 degradation as cells enter S phase (Baldin et al. 1993; Lukas et al. 1994). These results are consistent with the idea that phosphorylation of cyclin D1 depends in some manner on CDK4 assembly and may in turn regulate cyclin Dl turnover. Here, we present direct evidence that phosphorylation of cyclin D1 on a single threonine residue triggers D1 ubiquitination and its subsequent degradation by the proteasome.

Cyclin D1 is phosphorylated in mammalian cells on both threonine and serine residues. However, the two major tryptic phosphopeptides (designated A and B) con- 
tained only phosphothreonine, implying that serine phosphorylation occurs substoichiometrically at many sites. When coexpressed with CDK4 in Sf9 cells, cyclin D1 was again phosphorylated on peptides A and B. Twodimensional tryptic mapping of wild-type and mutant D1 proteins recovered from Sf9 cells failed to demonstrate phosphopeptides $\mathrm{A}$ and $\mathrm{B}$ in digests of a D1 (T286A) mutant, whereas a D1 (T286S) mutant yielded variant peptides containing phosphoserine in lieu of phosphothreonine. Therefore, Thr-286 is the major site of cyclin D1 threonyl phosphorylation in vivo, and the generation of two Thr-286-containing peptides must reflect incomplete tryptic digestion at a residue flanking this site.

\section{Thr-286 phosphorylation depends on, but does not} require, CDK4

Phosphorylation of cyclin D1 on Thr-286 in Sf9 cells proceeded without CDK4 coexpression but was reduced five- to eightfold in the absence of the catalytic subunit. When cyclin D1 was coexpressed in Sf9 cells together with either of two catalytically inactive CDK4 mutants, its phosphorylation in complexes with CDK4 was increased to a similar extent as that observed in complexes with the wild-type catalytic subunits, and mapping of the tryptic phosphopeptides indicated that spots A and B again represented the major sites of $\mathrm{D} 1$ modification. Mutant T172A and K35M CDK4 molecules were assembled into complexes with cyclin $\mathrm{Dl}$ but lacked $\mathrm{Rb}$ kinase activity. Therefore, although its assembly with CDK4 facilitated phosphorylation of D1, another protein kinase is able to carry out Thr-286 phosphorylation in Sf9 cells. Modification of cyclin D-CDK4 complexes by host cell mediated phosphorylation in Sf9 cells is not unprecedented. As exemplified above, activation of the holoenzyme requires the phosphorylation of cyclin $D$ bound CDK 4 on Thr-172 by the host cell CAK (Kato et al. 1994), a feature that is similarly required for activation of cyclin D-CDK4 in mammalian cells (Matsuoka et al. 1994).

Wild-type D1 was also phosphorylated when its expression was enforced in quiescent mammalian fibroblasts under conditions in which assembly with CDK4 did not occur. Therefore, the increase observed previously in cyclin D1 phosphorylation as cells enter the cycle and progress toward $S$ phase may at least in part reflect the propensity of an exogenous kinase to phosphorylate cyclin D1 more efficiently when it is complexed to CDK4. Although our data fail to implicate CDK4 in mediating cyclin D1 phosphorylation at Thr286, they do not formally exclude its participation in growth factor-stimulated cells, particularly with regard to phosphorylation of cyclin D1 on serine residues.

Given the periodicity of cyclin D1 hyperphosphorylation near the $G_{1} / S$ transition (Matsushime et al. 1991, 1994), we considered the conceptually attractive possibility that cyclin D1-CDK4 complexes might be phosphorylated by cyclin E-CDK2, thereby helping to limit cyclin D-dependent kinase activity as cyclin $\mathrm{E}$ synthesis becomes maximal. However, coexpression of cyclin D1 or of catalytically inactive cyclin D1-CDK4 complexes, together with enzymatically active cyclin E-CDK2 complexes in insect $\mathrm{Sf} 9$ cells, provided no evidence that cyclin D1 was an E-CDK2 substrate. Nor did coexpression of the CDK inhibitor $\mathrm{p} 27^{\mathrm{Kipl}}$, together with cyclin D1CDK4 in this system, block incorporation of ${ }^{32} \mathrm{P}$ into cyclin D1, which we confirmed was still phosphorylated on the Thr-286-containing peptides A and B /data not shown). Although it is flanked by a carboxy-terminal prolyl residue, Thr-286 in cyclin D1 is not a canonical CDK phosphorylation site; the analogous sites in cyclins D2 and D3 are similar in context and position and also lack the basic residues that usually accompany CDK recognition sequences (T/S-P-X-K/R). The ability of cyclin D1 to be phosphorylated in quiescent fibroblasts under conditions where $\mathrm{p} 27^{\mathrm{Kip} 1}$ levels are elevated and cyclin E-CDK2 complexes are inactive also argues against cyclin E-CDK2 involvement, at least in this setting.

\section{Cyclin D1 (T286A) is stable whether complexed to CDK4 or not}

Following its induction in proliferating mammalian fibroblasts, the half-life of the D1 (T286A) mutant was prolonged significantly $(-3.5 \mathrm{hr})$ as compared with that of wild-type cyclin D1 ( $30 \mathrm{~min})$. Because the Flag-tagged and wild-type Dl proteins could be electrophoretically resolved from one another, we could readily confirm that the endogenous wild-type and ectopically expressed mutant proteins, while cosynthesized in the same cells at the same rates, underwent degradation with markedly different kinetics. Neither the addition of an amino-terminal Flag tag nor mutation of Thr-286 to alanine or serine affected the ability of cyclin D1 to assemble into catalytically active complexes with CDK4 in insect Sf9 or in mouse NIH-3T3 cells. Immunofluorescence staining revealed that like wild-type D1 (Baldin et al. 1993), the D1 (T286A) mutant localized to nuclei (data not shown!.

In the case of cyclin $\mathrm{E}$ where autophosphorylation on Thr- 380 by CDK 2 triggers its turnover, the role of phosphorylation could be to untether the cyclin from CDK2, thereby facilitating its subsequent ubiquitination (Clurman et al. 1996; Won and Reed 1996). For several reasons, such a mechanism is unlikely to account for the effect of the T286A mutation on cyclin D1 turnover. In proliferating mouse macrophages, no significant differences were noted previously in the rates of turnover of the total D1 pool $\left(t^{1 / 2}=20-30 \mathrm{~min}\right)$ versus the fraction that was bound to CDK4 (Matsushime et al. 1992). In another independent study, the calculated half-lives of the free and CDK-bound cyclin D1 species in human cells were 12 and $27 \mathrm{~min}$, respectively, suggesting that CDK binding might protect cyclin D1 from being degraded (Bates et al. 1994), but not nearly to the extent observed with the cyclin D1 (T286A) mutant $\left(t^{1 / 2}=3.5\right.$ $\mathrm{hr}$ ). Neither is prior assembly with CDK4 required for rapid cyclin D1 turnover. Although cyclin D1 is not normally synthesized in growth factor-deprived cells, the 
machinery governing cyclin D1 turnover remains functionally intact. When cyclin D1 was ectopically expressed in quiescent mammalian fibroblasts under conditions where assembly with CDK4 is precluded, uncomplexed wild-type D1 subunits were phosphorylated (see above) and unstable. Conversely, CDK4 was not required to stabilize mutant D1 (T286A) subunits, which turned over much more slowly when induced in quiescent cells.

\section{Thr-286 phosphorylation affects cyclin} D1 ubiquitination

Treatment of mouse fibroblasts with the proteasome inhibitor LLnL, but not a control peptide aldehyde LLM, resulted in the accumulation of phosphorylated, high molecular weight forms of cyclin Dl, implying that these forms represent intermediates in the cyclin D1 degradation pathway. Therefore, we explored the possibility that cyclin D1 was ubiquitinated and that this modification depended on the integrity of Thr-286. When NIH-3T3 cells engineered to overexpress cyclin D1 were transfected with a plasmid encoding HA-ubiquitin and then treated with LLnL, high molecular weight polyubiquitinated proteins were detected in anti-D1, but not control, immunoprecipitates. Similarly, when FlagD1 was precipitated from LLnL-treated cells with a monoclonal antibody directed to the amino-terminal tag, polyubiquitinated proteins were again detected using antibodies to ubiquitin itself. Under the same conditions, immunoprecipitates containing D1 (T286A) were devoid of polyubiquitinated species. The simplest interpretation, then, is that phosphorylation of cyclin D1 at Thr286 triggers its ubiquitination and subsequent degradation.

However, when LLnL-treated cells expressing HAubiquitin were immunoprecipitated with anti-HA and then blotted with antibodies to cyclin D1, no high molecular weight Dl complexes were detected. Although technical limitations could well have accounted for the negative results (see Results pertaining to Fig. 1), this leaves open the possibility that a protein coprecipitating with cyclin D1, rather than Dl itself, undergoes polyubiquitination in LLnL-treated cells and that its association with D1 depends on the integrity or phosphorylation state of Thr-286. CDK4 was not suspect, as it readily formed complexes with D1 (T286A), but other candidate substrates for ubiquitination could include CDK inhibitors or proliferating cell nuclear antigen (PCNA), which can coprecipitate with cyclin D1-CDK4 complexes (Xiong et al. 1992; Zhang et al. 1993; Pagano et al. 1995), or other putative adaptor proteins that might potentially target phosphorylated cyclin Dl to the proteasome (Bai et al. 1996).

We therefore reconstituted an in vitro system in an attempt to demonstrate that cyclin D1 could be ubiquitinated. Sf9 extracts containing phosphorylated cyclin D1 and CDK4 were combined with extracts containing HA-ubiquitin and incubated in the presence of ATP, after which immunoprecipitates prepared with antibodies to the HA epitope or to cyclin D1 were separated on gels and blotted with the reciprocal antibody. In these reactions, cyclin D1 precipitates were again found to contain polyubiquitinated proteins, but here, anti-HA precipitates were also demonstrated to contain high molecular weight forms of cyclin D1. Moreover, if the in vitro reaction mixtures were boiled in SDS prior to immunoprecipitation with anti-D1, the resulting precipitates still contained HA-reactive material, indicating that ubiquitin was covalently linked to D1 itself. Importantly, polyubiquitination was not detected when D1 (T286A) was substituted for wild-type $\mathrm{Dl}$ in these reactions. Although these results do not formally exclude the participation of other coprecipitating proteins as targets of the ubiquitinating reaction, they argue that cyclin D1 can itself undergo polyubiquitination in a manner dependent on the integrity of Thr-286. Based on results using LLnL, we presume that phosphorylation and subsequent ubiquitination are preludes to proteasomal degradation.

\section{Comparative features of cyclin D1 and cyclin E turnover}

With only negative evidence that CDK4 contributes to cyclin D1 stability or degradation, we favor the concept that the Thr-286 phosphorylated form of D1 is targeted more readily by E2/E3 complexes than the unphosphorylated species, regardless of whether DI is free or bound to CDK4. Although it is entirely possible that substitution of amino acids other than alanine for Thr-286 might not inhibit cyclin D1 turnover as significantly, indirect evidence that cyclin D1 can be phosphorylated by an as yet uncharacterized kinase at this site and that this phosphorylation is physiologically meaningful raise the question of how the latter enzyme is itself controlled. In principle, the cyclin D protein kinase (or DPK) might itself be regulated by growth factors, suggesting yet another mechanism by which extracellular signals might regulate cyclin D-dependent kinases. Cyclin E turnover via ubiquitin-dependent proteolysis is regulated through its phosphorylation on Thr-380, but this reaction is catalyzed by its catalytic partner CDK2. The fact that cyclin E catalyzes its own destruction, whereas cyclin D1 does not further underscores the distinctions between growth factor-regulated (D-type) and cell cycle-regulated (E-type) mammalian $G_{1}$ cyclins.

\section{Materials and methods}

Cell lines, culture conditions, and transfection

$\mathrm{NIH}-3 \mathrm{~T} 3$ cells and their derivatives were grown in Dulbecco's modified Eagle's medium (DMEM) supplemented with $10 \%$ fetal calf serum (FCS), glutamine, and antibiotics (GIBCO). Insect Sf9 cells were maintained in Grace's medium containing 5\% heat-inactivated FCS (Summers and Smith 1987). NIH-3T3 cell derivatives (3T3-D1 cells) engineered to overexpress mouse cyclin Dl were established previously, and their properties were described in detail (Quelle et al. 1993). Additional cell lines engineered to express zinc-inducible, Flag-tagged cyclin D1 or D1 missense mutants at codon 286 were generated by transfec- 
tion using the calcium phosphate technique (Chen and Okayama 1987) with expression plasmids (see below) containing cyclin D1 cDNA under the control of the sheep metallothionein promoter (Inaba et al. 1996). Transfected cell lines were selected for 2 weeks in $800 \mu \mathrm{g} / \mathrm{ml}$ of G418 (Sigma Chemicals, St. Louis, $\mathrm{MO}$ and subsequently maintained in complete culture medium containing $400 \mu \mathrm{g} / \mathrm{ml}$ of the drug. Expression of Flag-tagged cyclin D1 proteins was induced by addition of 80 $\mu \mathrm{M} \mathrm{ZnSO}_{4}$ to the medium for the times indicated in the text and in the legends to Figures 4, 5, and 6. The peptide aldehydes LLnL and LLM (Sigma Chemicals, St Louis, MO) were solubilized at a final concentration of $20 \mathrm{~mm}$ in DMSO. Cells were treated with aldehydes diluted to 50-200 $\mu \mathrm{M}$ or with DMSO solvent alone as indicated in the legends to Figures 1 and 6 and were lysed prior to protein analysis (see below) in the presence of 5 mM N-ethylmaleimide (NEM) (Sigma Chemicals) to inhibit ubiquitin hydrolases.

\section{Construction of cyclin D1 mutants and expression vectors}

Cyclin D1 T286A and T286S mutants were each generated by two-step PCR as described previously (Kato et al. 1994) with the following oligonucleotide primers: 5 '-GAATTCGGCCGCGCCATGGAACACCAGCTCCTG [an "upstream" primer representing cyclin D1 sense-strand sequences flanked by a 5 '-EcoRI site (underlined) and containing the D1 initiator codon (also underlined)]; 5'-GGATCCTCAGATGTCCACATCTCG [a "downstream" primer inversely complementary to 3' cyclin D1 sequences flanked by a $5^{\prime}$-BamHI site (underlined) and the adjacent D1 stop codon (TGA in sense strand; TCA in antisense also underlined)]; 5'-GGTCTGGCCTGCGCGCCCACCGAC (T286A, sense strand, codon 286 underlined); 5'-GTCGGTGGGCGCGCAGGCCAGACC (T286A, antisense strand); 5'-GGTCTGGCCTGCTCGCCCACCGAC (T286S, sense strand, codon 286 underlined); and 5'-GTCGGTGGGCGAGCAGGCCAGACC (T286S, antisense strand). The template was cyclin D1 cloned into pBluescript (Matsushime et al. 1991). PCR was first performed with either the upstream primer and an antisense oligonucleotide containing mutated codon Thr286 or the downstream primer and the sense oligonucleotide containing mutated codon Thr-286. The two PCR products purified from gels were mixed and joined by amplification using the upstream and downstream primers. The final PCR products were cloned into PCR 2.1 (TA cloning vector; Invitrogen, San Diego, CA) and resequenced in their entirety. Cyclin D1 cDNA clones containing the programmed codon Thr-286 mutations and lacking adventitious base changes were selected for further analysis.

Mutated and wild-type cyclin D1 cDNAs were inserted into a mammalian expression vector (pFLEX1) and transiently expressed in mammalian cells under the control of an artificial promoter composed of SV40 early promoter sequences fused to the R-U5 sequences of the human $\mathrm{T}$ cell lymphotropic virus long terminal repeat (Bram and Crabtree 1994). The polylinker cloning site $3^{\prime}$ of the pFLEXl promoter is flanked by a 5 ' initiator codon followed by sequences encoding the Flag epitope (Met-Asp-Tyr-Lys-Asp ${ }_{4}$-Lys). Full-length cyclin D1 cDNAs and $3^{\prime}$ flanking plasmid sequences were excised with EcoRI from PCR 2.1 and inserted into the EcoRI cloning site of pFLEX1, thereby creating the Flag epitope fusion to cyclin D1. Following documentation of Flag-tagged D1 expression after transient transfection of pFLEX1 derivatives into NIH-3T3 cells, the Flag-D1 coding sequences were excised from pFLEX1 with BamHI and inserted into the BamHI cloning site of pMTCB6+, a mammalian expression vector containing the zinc-inducible sheep metallothionein promoter (Inaba et al. 1996). For expression of Flag-tagged cyclin D1 constructs in Sf9 cells, the BamHI fragment used above was inserted into the baculoviral vector pVL1393 (PharMingen, San Diego, CA). The HA-ubiquitin plasmid was obtained from Bruce Clurman (Fred Hutchinson Cancer Center, Seattle, WA) with permission from L. Staszewski and D. Bohman (Treier et al. 1994). cDNA sequences encoding HA-tagged ubiquitin were excised from the parental plasmid with NotI and EcoRI and inserted into pVL1392. Procedures for manipulation of baculoviruses were described previously (Matsushime et al. 1992; Kato et al. 1993) and were based on detailed experimental protocols of others (Summers and Smith 1987).

\section{Immunoprecipitation, immunoblotting, and kinase assays}

For all assays except $\mathrm{Rb}$ protein kinase assays, cells were lysed in buffer containing $50 \mathrm{~mm}$ Tris- $\mathrm{HCl}(\mathrm{pH} 7.5), 150 \mathrm{~mm} \mathrm{NaCl}$, $1 \%$ NP-40, $1 \%$ deoxycholate, $0.1 \%$ SDS, $1 \mathrm{~mm} \mathrm{PMSF}, 20 \mathrm{U} / \mathrm{ml}$ of aprotinin, $5 \mathrm{mg} / \mathrm{ml}$ of leupeptin, $1 \mathrm{~mm} \mathrm{DTT}, 0.4 \mathrm{~mm} \mathrm{NaF}, 0.4$ $\mathrm{mM} \mathrm{NaVO}_{4}$, and $5 \mathrm{~mm} \mathrm{NEM}$. For preparation of immune complexes that support $\mathrm{Rb}$ kinase activity, cells were lysed in buffer containing $50 \mathrm{~mm}$ HEPES ( $\mathrm{pH} 8.0$ ), $150 \mathrm{~mm} \mathrm{NaCl}, 2.5 \mathrm{~mm}$ EGTA, 1 mM EDTA, $0.1 \%$ Tween 20 , and protease and phosphatase inhibitors as described above (Matsushime et al. 1994). Lysates were cleared by centrifugation, and protein concentrations were determined with a commercial assay (Bio-Rad, Hercules, CA). Cyclin D1 or the Flag-tagged D1 derivatives were immunoprecipitated with either a mouse monoclonal antibody (D1-72-13G) directed to cyclin D1 (Vallance et al. 1993) or with the M2 mouse monoclonal antibody that specifically recognizes the Flag epitope tag (Kodak, New Haven, CT). Immune complexes were purified using Gamma-bind Sepharose (Pharmacia, Uppsala, Sweden). Samples were normalized for protein concentration prior to immune precipitation for all determinations, including $\mathrm{Rb}$ protein kinase assays, immunoprecipitation, immunoblotting, and tryptic peptide mapping.

For immunoblotting analyses, proteins were separated by electrophoresis in polyacrylamide gels containing SDS and then transferred to nitrocellulose (Millipore, Bedford, MA) and blotted (Downing et al. 1988) with the indicated primary antibodies. Antibodies to ubiquitin were commercially obtained (Zymed, San Francisco, CA), and those to the HA epitope were affinity purified and generously provided by Dr. Albert Reynolds (Vanderbilt University, Nashville, TN). Reactive products were visualized using protein A-conjugated horseradish peroxidase (EY Laboratories, San Mateo, CA) followed by chemiluminescent detection (ECL detection kit; Amersham, Arlington Heights, IL). In some experiments, filters were "stripped" according to the manufacturer's instructions and reprobed with other antibodies using the same procedure.

$\mathrm{Rb}$ protein kinase assays were performed as described previously (Matsushime et al. 1994). In brief, 800 ng of bacterially expressed glutathione $S$-transferase-Rb (GST-Rb) (Ewen et al. 1993 ) in $20 \mu \mathrm{l}$ of kinase buffer (50 mM HEPES at pH 7.5, $10 \mathrm{~mm}$ $\mathrm{MgCl}_{2}, 1 \mathrm{~mm}$ DTT, $1 \mathrm{~mm}$ EGTA, $0.4 \mathrm{~mm} \mathrm{NaVO}_{4}, 0.4 \mathrm{~mm} \mathrm{NaF}$, and $20 \mu \mathrm{M}$ unlabeled ATP) was mixed with immune complexes containing Flag-tagged D1 proteins or included $2 \mu \mathrm{l}$ of Sf9 lysates (corresponding to $\sim 5 \times 10^{4}$ cell equivalents) from cells infected with the indicated cyclins and CDKs. Kinase reactions were initiated by the addition of $10 \mu \mathrm{Ci}$ of $\left[\gamma^{-32}\right.$ P]ATP $(6000$ $\mathrm{Ci} / \mathrm{mmole}$; NEN, Boston, MA) and were incubated at $30^{\circ} \mathrm{C}$ for 15-25 min (with linear incorporation kinetics) depending on the source of enzyme. Labeled products were denatured in SDS sample buffer and separated on denaturing polyacrylamide gels prior to autoradiography. 


\section{Metabolic labeling and measurements of protein turnover}

3T3-D1 cells or Sf9 cells infected with the indicated baculoviruses were washed twice with phosphate-free media followed by a 1 -hr preincubation with phosphate-free medium containing $10 \%$ dialyzed FCS (3T3-D) ) or 5\% dialyzed FCS (Sf9). 3T3-D1 and Sf9 cells were then labeled for $2 \mathrm{hr}$ in the same medium with $1 \mathrm{mCi} / \mathrm{ml}$ of carrier-free $\left[{ }^{32} \mathrm{P}\right]$ orthophosphate $[\mathrm{ICN}$; Costa Mesa, CA!

Following $\mathrm{ZnSO}_{4}$ treatment of proliferating or quiescent cells expressing wild-type or mutant Flag-tagged D1 for the periods of time indicated in the legend to Figure 5, cells were washed twice with methionine-free medium and preincubated for 30 min with methionine-free medium containing $10 \%$ dialyzed FCS and $80 \mu \mathrm{MnSO}_{4}$. Cells were labeled for $30 \mathrm{~min}$ in the same medium with $200 \mu \mathrm{Ci} / \mathrm{ml}$ of $\operatorname{Tran}^{35} \mathrm{~S}$ (NEN Corp.), washed extensively with PBS, and refed with DMEM containing $10 \%$ FCS, $80 \mu \mathrm{M} \mathrm{ZnSO}_{4}$, and $2 \mathrm{~mm}$ unlabeled methionine. At various times after termination of labeling, equal aliquots of cells were lysed, and labeled cyclin D1 was recovered by immunoprecipitation, separated on denaturing gels, and detected by autoradiography.

\section{Two-dimensional mapping of phosphate-labeled} tryptic peptides

Phosphate-labeled cyclin D1 was isolated by immunoprecipitation followed by electrophoretic separation on denaturing gels and transfer to Immobilon-P membranes (Millipore). After visualization of cyclin D1 by autoradiography, pieces of filters containing cyclin D1 were excised and subjected to trypsin digestion (Rettenmier et al. 1985; Boyle et al. 1991). Phosphorylated, soluble cyclin D1 tryptic peptides were analyzed by electrophoresis in $\mathrm{pH} 1.9$ buffer in the first dimension and ascending chromatography in the second dimension as described (Kato et al. 1994). Thin-layer chromatography plates were subjected to autoradiography or PhosphorImaging (Molecular Dynamics 425F, Sunnyvale, CA) as indicated in the legends to Figures 2, 3, and 8 . For phosphoamino acid analysis, phosphorylated tryptic peptides were eluted in $\mathrm{pH} 1.9$ buffer, lyophilized, and hydrolyzed in $6 \mathrm{M} \mathrm{HCl}$ for $1 \mathrm{hr}$ at $100^{\circ} \mathrm{C}$ (Rettenmier et al. 1985). Phosphoamino acids were separated by two-dimensional electrophoresis (Rettenmier et al. 1985; Boyle et al. 1991) using an HTLE-7000 apparatus (CBS Scientific, Del Mar, CA); mixed internal standards were visualized with ninhydrin spray and ${ }^{32} \mathrm{P}$ labeled amino acids by PhosphorImaging.

\section{In vitro ubiquitination assay}

Sf9 cells infected with baculovirus encoding HA-tagged ubiquitin or coinfected with baculoviruses encoding CDK4 and the indicated cyclin Dl proteins were lysed in kinase buffer lacking ATP. Sf 9 lysates $\left(10 \mu \mathrm{l}\right.$, corresponding to $4 \times 10^{4}$ cell equivalents) containing equal amounts of either wild-type or mutant D1 proteins as determined by immunoblotting were mixed on ice with separately prepared Sf9 lysates $(20 \mu l$, corresponding to $2 \times 10^{5}$ cell equivalents) from cells infected with baculovirus encoding HA-ubiquitin. The mixtures were adjusted to $40 \mu \mathrm{l}$ in ubiquitination buffer / to final concentrations of $50 \mathrm{~mm}$ Tris$\mathrm{HCl}$ ( $\mathrm{pH} 8.0$ ), $5 \mathrm{~mm} \mathrm{MgCl}_{2}, 5 \mathrm{~mm} \mathrm{CaCl}_{2}, 2 \mathrm{~mm}$ DTT, and $5 \mathrm{~mm}$ NEM), and reactions were initiated by the addition of $1 \mu l$ of 100 mM ATP followed by incubation at $37^{\circ} \mathrm{C}$ for the indicated periods of time. Reactions were terminated by dilution into $0.5 \mathrm{ml}$ of ice-cold RIPA buffer containing $0.1 \%$ SDS, protease inhibitors, and $5 \mathrm{mM}$ NEM. In some experiments, SDS was added directly to the reaction mixtures to a final concentration of
$0.5 \%$, which were boiled for $1 \mathrm{~min}$ before dilution into $0.5 \mathrm{ml}$ of ice-cold RIPA buffer lacking SDS. Cyclin D1 was recovered by precipitation with monoclonal antibody, separated on denaturing gels, and blotted with anti-HA. Alternatively, ubiquitinated proteins were recovered with antibody to HA, separated on gels, and blotted with antibody to D1.

\section{Acknowledgments}

We thank Shawn Hawkins, Joseph Watson, and Carol Bockhold for excellent technical assistance, Dr. Albert Reynolds for his generous gift of antibodies to the HA epitope, Drs. Bruce Clurman and Jim Roberts for the gift of the HA-ubiquitin plasmid, Dawn Quelle and Mangeng Cheng for comments on the manuscript, and our other laboratory colleagues for suggestions, advice, and support throughout the course of this work. This study was supported in part by the American Lebanese Syrian Associated Charities (ALSAC) of St. Jude Children's Research Hospital and by National Institutes of Health Cancer Center CORE grant CA-21765.

The publication costs of this article were defrayed in part by payment of page charges. This article must therefore be hereby marked "advertisement" in accordance with 18 USC section 1734 solely to indicate this fact.

\section{References}

Amon, A., S. Irniger, and K. Nasmyth. 1994. Closing the cell cycle circle in yeast: G2 cyclin proteoylsis initiated at mitosis persists until the activation of G1 cyclins in the next cell cycle. Cell 77: 1037-1050.

Bai, C., P. Sen, K. Hofmann, L. Ma, M. Goebl, J.W. Harper, and S.J. Elledge. 1996. SKP1 connects cell cycle regulators to the ubiquitin proteolysis machinery through a novel motif, the F-box. Cell 86: 263-274.

Baldin, V., J. Lukas, M.J. Marcote, M. Pagano, and G. Draetta. 1993. Cyclin D1 is a nuclear protein required for cell cycle progression in $\mathrm{G}_{1}$. Genes \& Dev. 7: 812-821.

Bates, S., D. Parry, L. Bonetta, K. Vousden, C. Dickson, and G. Peters. 1994. Absence of cyclin D/cdk4 complexes in cells lacking functional retinoblastoma protein. Oncogene 9: 1633-1640.

Boyle, W.J., P. Van der Geer, and T. Hunter. 1991. Protein phosphorylation, part B. Methods Enzymol. 201: 21-27.

Bram, R.J. and G.R. Crabtree. 1994. Calcium signaling in T cells stimulated by a cyclophilin B-binding protein. Nature 371 : 355-358.

Chen, C. and H. Okayama. 1987. High-efficiency transformation of mammalian cells by plasmid DNA. Mol. Cell. Biol. 7: 2745-2752.

Chen, Z., J. Hagler, V.J. Palombella, F. Melandri, D. Scherer, D. Ballard, and T. Maniatis. 1995. Signal-induced site-specific phosphorylation targets IKB $\alpha$ to the ubiquitin-proteasome pathway. Genes \& Dev. 9: 1586-1597.

Ciechanover, A. 1994. The ubiquitin-proteasome proteolytic pathway. Cell 79: 13-21.

Clurman, B.E., R.J. Sheaff, K. Thress, M. Groudine, and J.M. Roberts. 1996. Turnover of cyclin $\mathrm{E}$ by the ubiquitin-proteasome pathway is regulated by CDK2 binding and cyclin phosphorylation. Genes \& Dev. 10: 1979-1990.

Deshaies, R.J. 1995. Make it or break it: The role of ubiquitindependent proteolysis in cellular regulation. Trends Cell Biol. 5: 428-434.

Deshaies, R.J., V. Chau, and M. Kirschner. 1995. Ubiquitination of the G1 cyclin $C \ln 2$ p by a Cde34p-dependent pathway. 
$E M B O$ I. 14: 303-312.

Downing, J.R., C.W. Rettenmier, and C.J. Sherr. 1988. Ligandinduced tyrosine kinase activity of the colony stimulating factor-1 receptor in a murine macrophage cell line. Mol. Cell. Biol. 8: 1795-1799.

Dulic, V., E. Lees, and S.I. Reed. 1992. Association of human cyclin E with a periodic G1-S phase protein kinase. Science 257: 1958-1961.

Ewen, M.E., H.K. Sluss, C.J. Sherr, H. Matsushime, J. Kato, and D.M. Livingston. 1993. Functional interactions of the retinoblastoma protein with mammalian D-type cyclins. Cell 73: $487-497$.

Glotzer, M., A.W. Murray, and M.W. Kirschner. 1991. Cyclin is degraded by the ubiquitin pathway. Nature 349: 132-138.

Hilt, W. and D.H. Wolf. 1996. Proteasomes: Destruction as a programme. Trends Biochem. Sci. 21: 96-102.

Hirai, H. and C.J. Sherr. 1996. Interaction of D-type cyclins with a novel myb-like transcription factor, DMP1. Mol. Cell. Biol. 16: $6457-6467$.

Inaba, T., T. Inukai, T. Yoshihara, H. Seyschab, R.A. Ashmun, C.E. Canman, S.J. Laken, M.B. Kastan, and A.T. Look. 1996. Reversal of apoptosis by the leukaemia-associated E2A-HLF chimaeric transcription factor. Nature 382: 541-544.

Irniger, S., S. Piatti, C. Michaelis, and K. Nasmyth. 1995. Genes involved in sister chromatid separation are needed for B-type cyclin proteoylsis in budding yeast. Cell 81: 269-277.

Jentsch, S. and S. Schlenker. 1995. Selective protein degradation: A journey's end within the proteasome. Cell 82: 881884.

Kato, J., H. Matsushime, S.W. Hiebert, M.E. Ewen, and C.J. Sherr. 1993. Direct binding of cyclin D to the retinoblastoma gene product $(\mathrm{pRb})$ and $\mathrm{pRb}$ phosphorylation by the cyclin D-dependent kinase, CDK4. Genes \& Dev. 7: 331-342.

Kato, J., M. Matsuoka, D.K. Strom, and C.J. Sherr. 1994. Regulation of cyclin D-dependent kinase 4 (cdk4) by cdk4-activating kinase. Mol. Cell. Biol. 14: 2713-2721.

King, R.W., J.-M. Peters, S. Tugendreich, M. Rolfe, P. Hieter, and M.W. Kirschner. 1995. A 20 S complex containing CDC27 and CDC16 catalyzes the mitosis-specific conjugation of ubiquitin to cyclin B. Cell 81: 279-288.

King, R.W., R.J. Deshaies, J.-M. Peters, and M.W. Kirschner. 1996. How proteolysis drives the cell cycle. Science 274: 1652-1659.

Kitagawa, M., H. Higashi, H.-K. Jung, I. Suzuki-Takahashi, M. Ikeda, K. Tamai, J. Kato, K. Segawa, E. Yoshida, S. Nishimura, and Y. Taya. 1996. The consensus motif for phosphorylation by cyclin D1-cdk4 is different from that for phosphorylation by cyclin A/E-cdk2. EMBO I. 15: 70607069.

Koff, A., A. Giordano, D. Desai, K. Yamashita, J.W. Harper, S. Elledge, T. Nishimoto, D.O. Morgan, B.R. Franza, and J.M. Roberts. 1992. Formation and activation of a cyclin E-cdk2 complex during the G1 phase of the human cell cycle. Science 257: 1689-1694.

Krude, T., M. Jackman, J. Pines, and R.A. Laskey. 1997. Cyclin/ cdk-dependent initiation of DNA replication in a human cell-free system. Cell 88: 109-119.

Lanker, S., M.H. Valdivieso, and C. Wittenberg. 1996. Rapid degradation of the G1 cyclin Cln2 induced by CDK-dependent phosphorylation. Science 271: 1597-1601.

Lukas, J., M. Pagano, Z. Staskova, G. Draetta, and J. Bartek. 1994. Cyclin Dl protein oscillates and is essential for cell cycle progression in human tumor lines. Oncogene 9: 707718.

Lukas, J., J. Bartkova, M. Rohde, M. Strauss, and J. Bartek. 1995. Cyclin D1 is dispensable for G1 control in retinoblastoma gene-deficient cells, independent of CDK4 activity. Mol. Cell. Biol. 15: 2600-2611.

Matsuoka, M., J. Kato, R.P. Fisher, D.O. Morgan, and C.J. Sherr. 1994. Activation of cyclin-dependent kinase-4 (CDK4) by mouse MO15-associated kinase. Mol. Cell. Biol. 14: 72657275.

Matsushime, H., M.F. Roussel, R.A. Ashmun, and C.J. Sherr. 1991. Colony-stimulating factor 1 regulates novel cyclins during the G1 phase of the cell cycle. Cell 65: 701-713.

Matsushime, H., M.E. Ewen, D.K. Strom, I. Kato, S.K. Hanks, M.F. Roussel, and C.J. Sherr. 1992. Identification and properties of an atypical catalytic subunit (p34 ${ }^{\text {PSK-J3 }} /$ CDK4) for mammalian D-type G1 cyclins. Cell 71: 323-334.

Matsushime, H., D.E. Quelle, S.A. Shurtleff, M. Shibuya, C.J. Sherr, and J. Kato. 1994. D-type cyclin-dependent kinase activity in mammalian cells. Mol. Cell. Biol. 14: 2066-2076.

Morgan, D.O. 1995. Principles of cdk regulation. Nature 374: $131-134$.

Norbury, C. and P. Nurse. 1992. Animal cell cycles and their control. Annu. Rev. Biochem. 61: 441-470.

Ohtsubo, M. and J.M. Roberts. 1993. Cyclin-dependent regulation of G1 in mammalian fibroblasts. Science 259: 19081912.

Ohtsubo, M., A.M. Theodoras, J. Schumacher, J.M. Roberts, and M. Pagano. 1995. Human cyclin E, a nuclear protein essential for the G1 to $S$ phase transition. Mol. Cell. Biol. 15: 2612-2624.

Pagano, M., S.W. Tam, A.M. Theodoras, P. Beer-Romano, G. Dal Sal, V. Chau, P.R. Yew, G.F. Draetta, and M. Rolfe. 1995. Role of the ubiquitin-proteasome pathway in regulating abundance of the cyclin-dependent kinase inhibitor p27. Science 269: 682-685.

Peters, J.-M., R.W. King, C. Hoog, and M.W. Kirschner. 1996. Identification of BIME as a subunit of the anaphase-promoting complex. Science 274: 1199-1201.

Quelle, D.E., R.A. Ashmun, S.A. Shurtleff, J. Kato, D. Bar-Sagi, M.F. Roussel, and C.J. Sherr. 1993. Overexpression of mouse D-type cyclins accelerates $G_{1}$ phase in rodent fibroblasts. Genes \& Dev. 7: 1559-1571.

Reed, S.I. 1992. The role of p34 kinases in the G1 to S-phase transition. Annu. Rev. Cell Biol. 8: 529-561.

Resnitzky, D., M. Gossen, H. Bujard, and S.I. Reed. 1994. Acceleration of the G1/S phase transition by expression of cyclins D1 and E with an inducible system. Mol. Cell. Biol. 14: $1669-1679$.

Rettenmier, C.W., J.H. Chen, M.F. Roussel, and C.J. Sherr. 1985. The product of the c-fms proto-oncogene: A glycoprotein with associated tyrosine kinase activity. Science 228: 320322 .

Rock, K.L., C. Gramm, L. Rothstein, K. Clark, R. Stein, L. Dick, D. Hwang, and A.L. Goldberg. 1994. Inhibitors of the proteasome block the degradation of most cell proteins and the generation of peptides presented on MHC class I molecules. Cell 78: 761-771.

Rogers, S., R. Wells, and M. Rechsteiner. 1986. Amino acid sequences common to rapidly degraded proteins: The PEST hypothesis. Science 234: 364-368.

Salama, S.R., K.B. Hendricks, and J. Thorner. 1994. G1 cyclin degradation: The PEST motif of yeast $C \ln 2$ is necessary, but not sufficient, for rapid protein turnover. Mol. Cell. Biol. 14: 7953-7966.

Seufert, W., B. Futcher, and S. Jentsch. 1995. Role of a ubiquitinconjugating enzyme in degradation of S- and M-phase cyclins. Nature 373: 78-81.

Sherr, C.J. 1993. Mammalian $\mathrm{G}_{1}$ cyclins. Cell 73: 1059-1065. . 1996. Cancer cell cycles. Science 274: 1672-1677. 
Diehl et al.

Sherr, C.J. and J.M. Roberts. 1995. Inhibitors of mammalian $G_{1}$ cyclin-dependent kinases. Genes \& Dev. 9: 1149-1163.

Sudakin, V., D. Ganoth, A. Dahan, H. Heller, J. Hershko, F.C. Luca, J.V. Ruderman, and A. Hershko. 1995. The cyclosome, a large complex containing cyclin-selective ubiquitin ligase activity, targets cyclins for destruction at the end of mitosis. Mol. Biol. Cell 6: 185-198.

Summers, M.D. and G.E. Smith. 1987. A manual of methods for baculovirus vectors and insect culture procedures. Tex. $\mathrm{Ag}$ ric. Exp. Stn. Bull. no. 1555.

Treier, M., L.M. Staszewski, and D. Bohman. 1994. Ubiquitindependent $\mathrm{c}$-jun degradation in vivo is mediated by the $\delta$ domain. Cell 78: 787-798.

Vallance, S.J., H. Lee, M.F. Roussel, S.A. Shurtleff, J. Kato, D.K. Strom, and C.J. Sherr. 1993. Monoclonal antibodies to mammalian D-type G1 cyclins. Hybridoma 13: 37-44.

Weinberg, R.A. 1995. The retinoblastoma protein and cell cycle control. Cell 81: 323-330.

Won, K.-A. and S.I. Reed. 1996. Activation of cyclin E/CDK2 is coupled to site-specific autophosphorylation and ubiquitindependent degradation of cyclin E. EMBO T. 15: 4182-4193.

Xiong, Y., H. Zhang, and D. Beach. 1992. D-type cyclins associate with multiple protein kinases and the DNA replication and repair factor PCNA. Cell 71: 505-514.

Yaglom, J., M.H.K. Linskens, S. Sadis, D.M. Rubin, B. Futcher, and D. Finley. 1995. p34 ${ }^{\mathrm{Cdc}-28}$-mediated control of Cln3 cyclin degradation. Mol. Cell. Biol. 15: 731-741.

Zhang, H., Y. Xiong, and D. Beach. 1993. Proliferating cell nuclear antigen and $\mathrm{p} 21$ are components of multiple cell cycle kinase complexes. Mol. Biol. Cell 4: 897-906. 


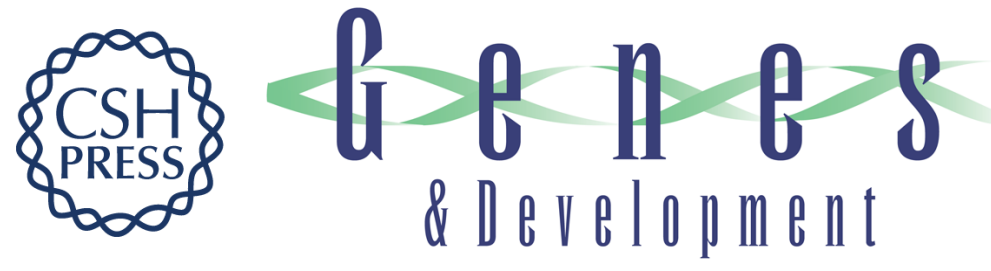

\title{
Inhibition of cyclin D1 phosphorylation on threonine-286 prevents its rapid degradation via the ubiquitin-proteasome pathway.
}

\author{
J A Diehl, F Zindy and C J Sherr
}

Genes Dev. 1997, 11:

Access the most recent version at doi:10.1101/gad.11.8.957

References This article cites 60 articles, 29 of which can be accessed free at: http://genesdev.cshlp.org/content/11/8/957.full.html\#ref-list-1

License

Email Alerting

Service

Receive free email alerts when new articles cite this article - sign up in the box at the top right corner of the article or click here.

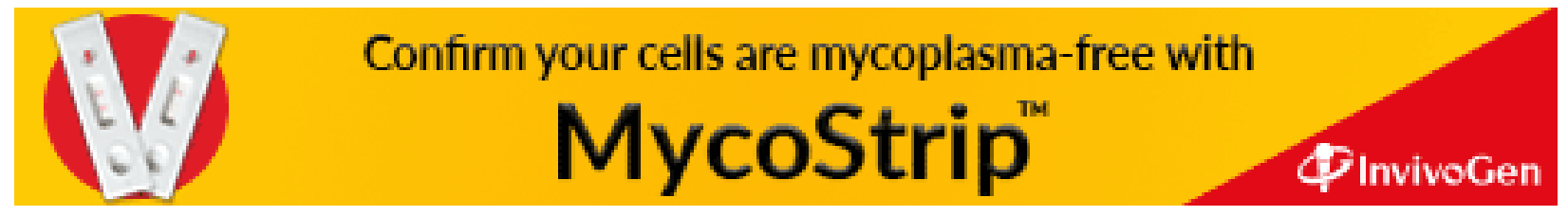

